Accepted version of

Hanel, P. H. P., Wolfradt, U., Coelho, G. L. de H., Wolf, L. J., Vilar, R., Monteiro, R. P., ... Maio, G. R. (2018). The perception of family, city, and country values is often biased. Journal of Cross-Cultural Psychology. https://doi.org/10.1177/0022022118767574

\title{
The Perception of Family, City, and Country Values is often Biased
}

Paul H. P. Hanel ${ }^{1,2^{*}}$, Uwe Wolfradt ${ }^{3}$, Gabriel Lins de Holanda Coelho ${ }^{2}$, Lukas J. Wolf $^{1,2}$, Roosevelt Vilar ${ }^{4}$, Renan Pereira Monteiro ${ }^{5}$, Valdiney V. Gouveia ${ }^{6}$, Tom Crompton ${ }^{7}$, Gregory R. Maio ${ }^{1}$

${ }^{1}$ Department of Psychology, University of Bath, Bath, United Kingdom

${ }^{2}$ School of Psychology, Cardiff University, United Kingdom

${ }^{3}$ Institut für Psychologie, Martin-Luther-Universität Halle-Wittenberg, Germany

${ }^{4}$ School of Psychology, Massey University, New Zealand

${ }^{5}$ Departamento de Psicologia, Universidade Federal do Piauí, Brazil

${ }^{6}$ Departamento de Psicologia, Universidade Federal da Paraíba, Brazil

${ }^{7}$ Common Cause Foundation, United Kingdom

* Please address correspondence to Paul Hanel, Department of Psychology, University of Bath, Claverton Down, BA2 7AY Bath, United Kingdom, p.hanel@bath.ac.uk or paulhanel@gmail.com

Acknowledgements: The authors acknowledge financial support from the CAPES Foundation (Brazil, http://www.capes.gov.br/) to Gabriel Lins, Conselho Nacional de Desenvolvimento Científico e Tecnológico (Brazil, http://cnpq.br/) to Roosevelt Vilar, and from the Big Lottery Fund England to Common Cause Foundation. The funders had no role in study design, data collection and analysis, decision to publish, or preparation of the manuscript.

Some findings from Study 2 have been summarized in lay-terms on the website of the not-for-profit Company Common Cause Foundation https://valuesandframes.org/greatermanchester/. 


\begin{abstract}
People often make inferences about the values of other people in their families, cities, and countries, but there are reasons to expect systematic biases in these inferences. Across four studies $(N=1,763)$, we examined people's perceptions of the values of their families, fellow citizens of the cities in which they live, and compatriots across three nations (Brazil, Germany, UK). Our results show that people systematically misperceive comparison groups' values. People underestimate the importance that their compatriots ascribe to more important values and overestimate the importance of less important values. This occurs in comparison to their own values, the actual values of the people living in the same city, and the actual values of their compatriots. The effect sizes were medium to large. Furthermore, the results occurred independently of participants' culture, time spent in the culture, and the underlying value model used. These results consistently show that people's speculations about values in their community and society are biased in a self- and family-favoring direction. Additionally, we found that the structure of values (e.g., as proposed by Schwartz, 1992) holds for perceived family, fellow citizens of the cities in which they live, and compatriots' values. Overall, our findings suggest that the values of other people are more selfless than is often believed.
\end{abstract}

Keywords: values, compatriots' values, perceived values, sojourners 


\section{The Perception of Family, City, and Country Values is often Biased}

Many people believe that the state of values within their society is deteriorating. For example, in $2016,73 \%$ of US-Americans believed that their country's values are getting worse rather than better (McCarthy, 2016), and in Germany, the expression "deterioration of values" is often used by politicians and the police to condemn negative developments and events (Heinemann, 2016). Further, some Brazilian right-wing politicians are promising that they will reinforce democratic and traditional Brazilian values which are, in their view, declining (Alvares, 2016). Statements about declining values rely on the assumption that people's perception of societal values is accurate. If the values of the society are misperceived, however, this would question claims about a decline in values. To the best of our knowledge, research has not tested how accurately people perceive the values of the city and country in which they are living. Across four studies and three countries, while using two value models, the present research provides the first direct examination of this accuracy.

\section{Human Values}

Contemporary psychological models define human values as abstract guiding principles in our life (Gouveia, 2013; Schwartz, 1992). For instance, according to Schwartz's circumplex model (1992), values can be organized along two orthogonal dimensions: selftranscendence versus self-enhancement values and openness versus conservation values (Figure 1). The former dimension contrasts benevolence and universalism values, which transcend personal interests to consider the welfare of others, with power and achievement values, which focus on promotion of the self. The other dimension contrasts conformity, security, and tradition values, which promote the status quo, with self-direction and stimulation values, which promote intellectual and emotional interests in uncertain directions. Hedonism falls between openness and self-enhancement values because it shares elements of both higher-order value types. Schwartz (1992) has found that this structure of values is 
almost universal, as supported by findings from over 70 countries (cf. Bilsky, Janik, \& Schwartz, 2011).

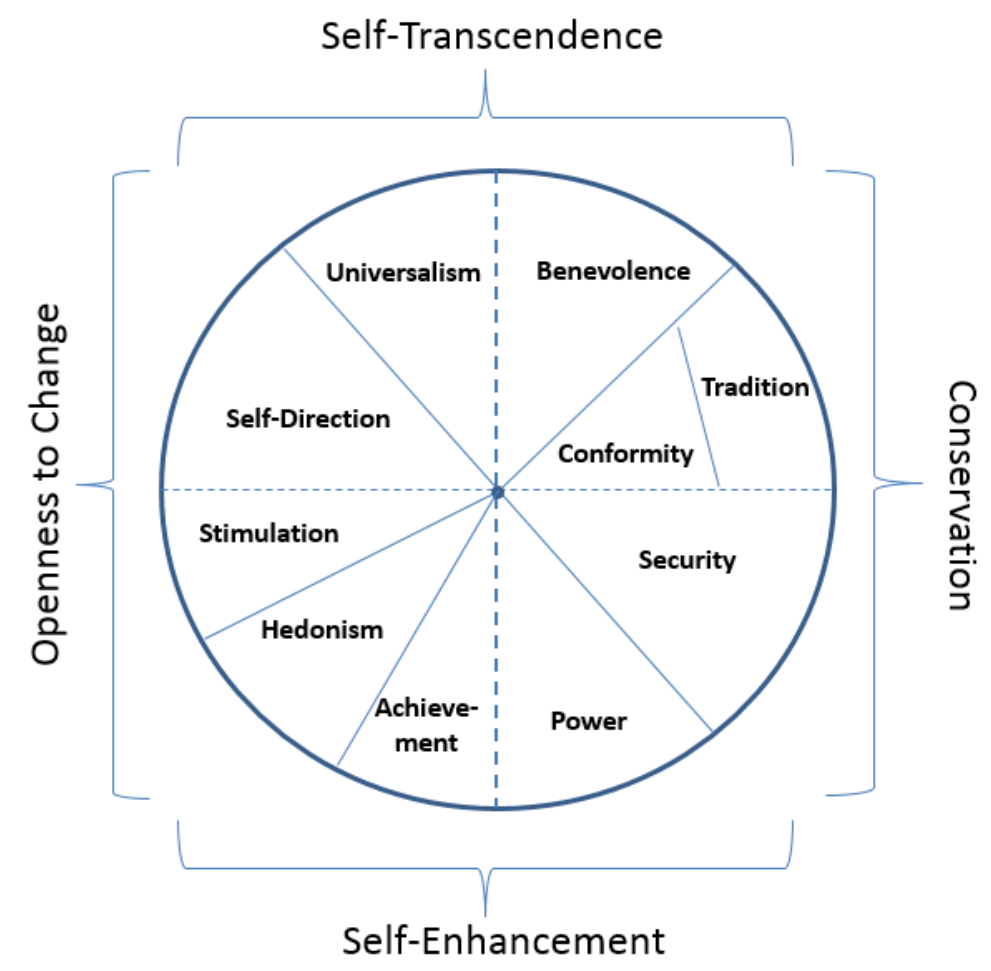

Figure 1. The value model of Schwartz (1992).

Another important cross-cultural finding is that there are large similarities in people's value priorities around the world. Across more than 56 countries and various samples, Schwartz and Bardi (2001) found that benevolence values (e.g., loyalty, helpfulness) are considered most important, followed by self-direction (e.g., freedom, independence) and universalism values (e.g., equality, wisdom). In contrast, stimulation (e.g., an exciting life, daring), tradition (e.g., respect for tradition, humble), and power values (e.g., wealth, authority) are considered least important. Schwartz and Bardi argue that benevolence values are rated on average as most important, because they "provide the internalized motivational base for cooperative and supportive social relations" (p. 281). In contrast, power values are considered to be least important because they might threaten positive social relations.

Another model of values is Gouveia's (2013) functional theory. This theory assumes that values can be ordered along two dimensions: goals and needs (Gouveia, Milfont, \& 
Guerra, 2014a). The first dimension outlines personal, central, and social goals, whereas the second dimension distinguishes between survival and thriving needs. Taken together, this model assumes six sub-functions (Figure 2). Although there are some differences between Gouveia's (2013) and Schwartz's (1992) models, both theorists agree that the content of the values is similar between the models (Gouveia, Milfont, \& Guerra, 2014b; Schwartz, 2014). For example, the promotion sub-function in Gouveia's theory contains values that overlap with the power and achievement domains (i.e., self-enhancement values) in Schwartz's theory, and the excitement sub-function is related to hedonism and stimulation values.

\begin{tabular}{|c|c|c|c|c|}
\hline & \multicolumn{3}{|c|}{ Values as guides of actions (circle of goals) } \\
\hline & & Personal goals & Central goals & Social goals \\
\hline 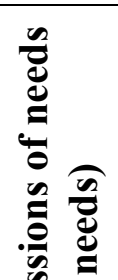 & $\begin{array}{c}\text { Thriving } \\
\text { needs }\end{array}$ & $\begin{array}{c}\text { Excitement Values } \\
\text { Emotion } \\
\text { Pleasure } \\
\text { Sexuality }\end{array}$ & $\begin{array}{c}\text { Suprapersonal Values } \\
\text { Beauty } \\
\text { Knowledge } \\
\text { Maturity }\end{array}$ & $\begin{array}{c}\text { Interactive Values } \\
\text { Affection } \\
\text { Belonging } \\
\text { Support }\end{array}$ \\
\hline 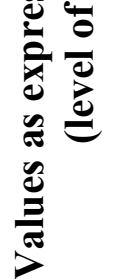 & $\begin{array}{c}\text { Survival } \\
\text { needs }\end{array}$ & $\begin{array}{c}\text { Promotion Values } \\
\text { Power } \\
\text { Prestige } \\
\text { Success }\end{array}$ & $\begin{array}{c}\text { Existence Values } \\
\text { Health } \\
\text { Stability } \\
\text { Survival }\end{array}$ & $\begin{array}{c}\text { Normative Values } \\
\text { Obedience } \\
\text { Religiosity } \\
\text { Tradition }\end{array}$ \\
\hline
\end{tabular}

Figure 2. The functional theory of human values. Adapted from Gouveia et al. (2014a).

\section{Perceptions of Other People}

In the present research, we compare people's own values with how they perceive the values of their families, fellow citizens of the cities in which they live, and compatriots in their society. In addition, we set out to test how accurately people perceive others' values. Based on previous research, we hypothesize that there are systematic differences in people's estimations of others' values - differences that are consistent with previous research examining perceptions of others' traits. People perceive moral traits, such as being reliable and honest, to be more characteristic for themselves than for the average person or student 
(Alicke, 1985; Alicke, Klotz, Breitenbecher, Yurak, \& Vredenburg, 1995; Alicke, Vredenburg, Hiatt, \& Govorun, 2001; Tappin \& McKay, 2017). In contrast, people perceive traits that are usually considered as negative, such as being disrespectful or snobbish, as less characteristic for themselves than for the average person. Recent research has found that this effect is persistent. For example, even prisoners consider themselves more prosocial than non-prisoners (Sedikides, Meek, Alicke, \& Taylor, 2014). In addition, the effect is larger among people with higher socio-economic status (Varnum, 2015), and made-up theories attributed to oneself are preferred more than theories attributed to strangers or no-one (Gregg, Mahadevan, \& Sedikides, 2017).

Testing whether this misperception of other people's characteristics also occurs in values is important because values are usually defined as primarily positive constructs (Hitlin \& Piliavin, 2004), which vary in their importance (Schwartz \& Bardi, 2001). Thus, all values are presumably perceived as at least somewhat characteristic for oneself (because there are no value equivalents to less desirable traits such as disrespectful or snobbish). Based on this attribute of values, one might expect that all values should be perceived to be equally or more important for oneself than for other people. However, an alternative hypothesis is that the misperception of other people's values is negated or reversed in values that are generally of lower importance. This moderation-by-value view is indirectly supported by a range of studies finding that certain values relate to outcomes that are generally considered to be negative. For example, the least important value type, power (Schwartz \& Bardi, 2001), was found to predict outcomes such as prejudice (Feather \& McKee, 2008; Souchon, Maio, Hanel, \& Bardin, 2017), negative attitudes towards the environment (Schultz \& Zelezny, 1999), or negative traits including callousness, hostility, and manipulativeness (Zacharopoulos et al., 2018). In contrast, universalism and benevolence were negatively related to these outcomes. Thus, some values may be perceived as less desirable, although they are still rated as important for oneself. Furthermore, everyday experiences with strangers may further result in 
an overestimation of other people's power, achievement, and hedonism values: Strangers are often encountered in settings which promote power and achievement values such as in a business context or in shopping malls. Indeed, people felt that business contexts would encourage self-enhancement values more than self-transcendence values - and vice versa for art galleries (Common Cause Foundation, 2016). Hence, we expect that individuals see themselves as higher in values that are commonly important (e.g., benevolence, self-direction, and universalism), but lower in other values that are commonly less important (e.g., power and stimulation). We discuss potential underlying mechanisms of this effect further in the General Discussion.

\section{The Present Research}

In the present studies, we test whether other people's values are perceived to be different than own values, whether other's values are misperceived and if so, whether this misperception occurs across all values in the same direction or is moderated by value type (i.e., are all values perceived to be more important for oneself than other people or are there some values which are perceived to be less important for oneself than other people?). In addition, we considered different comparison groups. Specifically, we compared participants' ratings of their own values with those of their own family, fellow citizens of their city, and compatriots in their society. We expected the misperceptions to occur in all of these comparisons. At the same time, however, we expected that the bias in perceiving values also extends beyond participants' own values to include groups to which they are strongly attached. Individuals have been shown to be motivated to rate their ingroups (which are psychologically closer to the self) more favorably than outgroups (Eriksson \& Funcke, 2015). Given that one's family can be expected to be more psychologically close to the self, participants may also see their own family as holding values that are morally superior to those held by the society in which they live. Thus, we also expected the difference between own and other people's values to be larger in self-compatriots comparisons than in self-family 
comparisons, because the family is usually considered as an ingroup and thus closer to the self (Tropp \& Wright, 2001).

Our research also addressed a deficit in cross-cultural comparisons. The above cited evidence for the existence of trait misperceptions originates from Western countries. However, cross-cultural research has found that the misperceptions of other people's traits was less pronounced or even non-existent in non-Western countries (Heine, Lehman, Markus, \& Kitayama, 1999; Markus \& Kitayama, 1991), especially for negative traits (Lee, 2012) or culturally unimportant traits (Tam et al., 2012). We therefore tested whether this finding can also be replicated by comparing two countries that are considered as Western (Germany and the UK) with one non-Western country (Brazil). This comparison is important because a significant portion of research findings from Western countries do not replicate in nonWestern countries (Henrich, Heine, \& Norenzayan, 2010). In addition, we considered whether the findings can be replicated in a sample of immigrants.

Finally, we tested across all studies whether the structure of human values for perceived family, fellow citizens of their city, and compatriots' values is the same as for participants' own values, which we report for Study 1 below and for Studies 2-4 in the Supplemental Materials. To the best of our knowledge, these aims have not been investigated before. The datasets for all studies and the Supplemental Materials can be found on https://osf.io/9agfd/?view_only=1422f9ae2a764ca18ce309ac50cc15ed

\section{Study 1}

Study 1 began examining our hypotheses using a student sample in Germany. The study enabled our first test of whether self-other differences and misperceptions occurs for all values or only for those values that are seen as more important. To perform this test, participants rated the importance of values from Schwartz's circular model across three targets: self, family, and country. Additionally, we tested whether the postulated circular 
structure of values holds for all target groups. This was also done to test the reliability of the value scales.

\section{Method}

Participants. Two-hundred and ten students from a German university completed the survey $\left(M_{\mathrm{age}}=22.21, S D=3.65,65 \%\right.$ women $)$ in 2013 . Most of them were studying various subjects (e.g., Mathematics, English) to become a teacher.

Material and Procedure. To measure participants' own values and their perceptions of their family's and country's values, we utilized a modified version of the 10-item Short Schwartz Value Survey (SSVS; Lindeman \& Verkasalo, 2005) in its German translation (Boer, 2014). Example items include "Achievement: Personal success through demonstrating competence according to social standards" and "Self-direction: Independent thought and action-choosing, creating, exploring”. Participants rated the importance of the values using a 6-point scale ranging from 1 (completely unimportant) to 6 (very important). We modified the SSVS in a way that participants first indicated the personal importance of a value type for them, followed by the importance for the family and country. Most participants completed the survey in one lecture hall and were not compensated.

Study 1 was part of a larger survey in which additionally personality traits (Big-5), self-esteem, and satisfaction with life were measured. None of this data is reported elsewhere, this includes manuscripts in preparation.

\section{Results and Discussion}

We first report the comparison of self-family, self-country, and family-country comparison, before we test whether the proposed structure of values (Figure 1; Schwartz, 1992) holds for family and compatriots' values. This test is also important to assess the reliability of the three value scales, because each value type was measured with a single item. Self-family value comparisons. We examined how participants perceived their own values compared to the values of their family with a set of within-subject $t$-tests. The effect sizes 
were computed using pooled standard deviations. Compared to their own value importance ratings, participants perceived their family as attaching more importance to conformity, and less importance to achievement, hedonism, stimulation, self-direction, universalism, and benevolence (Figure 3 and Table 1).

Self-compatriots' value comparisons. We examined how participants perceived their own values compared to the values of their country again with a set of within-subject $t$ tests. Compared to their own value importance ratings, participants perceived their country as attaching more importance to power and achievement, and less importance to hedonism, stimulation, self-direction, universalism, and benevolence (Figure 3 and Table 1). As predicted, the correlation between the importance of the 10 value types correlated positively with the self-country bias, $r(8)=.43$. Specifically, we correlated the importance of the own values (Table 1, column 2) with the Cohen's d of the self-country comparisons (Table 1, column 7). This suggests that people underestimate the importance their compatriots ascribe to more important values and overestimate the importance of less important values.

Family-compatriots' value comparisons. We examined how participants perceived their family values compared to the values of their country again with a set of within-subject $t$-tests. Compared to their family, participants perceived their country as attaching more importance to power, achievement, and stimulation and less importance to self-direction, universalism, benevolence, and security (Figure 3 and Table 1).

Table 1 shows that participants' perceptions of their family's values tended to be closer to their own values than to perceptions of their country's values. Correlational analyses supported this finding: The importance that the participants ascribed to all 10 value types correlated highly with the perceived importance of the values in their family $(.43<r<.70$, all $p \mathrm{~s}<.001)$, but not with the perceived importance of the values in their country $(-.11<r<.17$, $.02<p<.95)$.

Table 1 
Descriptive statistics and within-subject comparisons of perceived value importance for self, family, and country

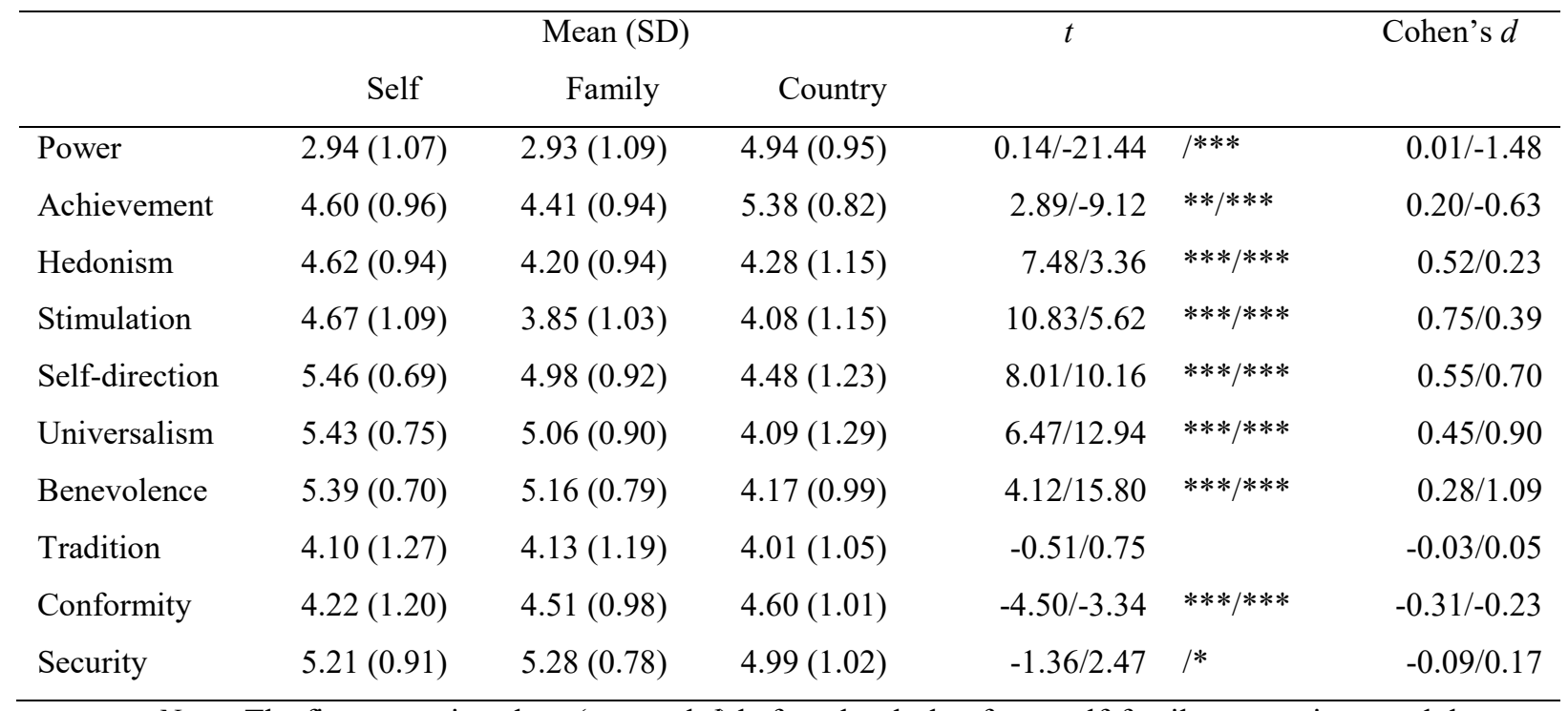

Note. The first numeric values $(t, p$, and $d$ ) before the slash refer to self-family comparison, and the numbers after the slash refer to the self-country comparison. $D f$ s were between 207 and 209, respectively.

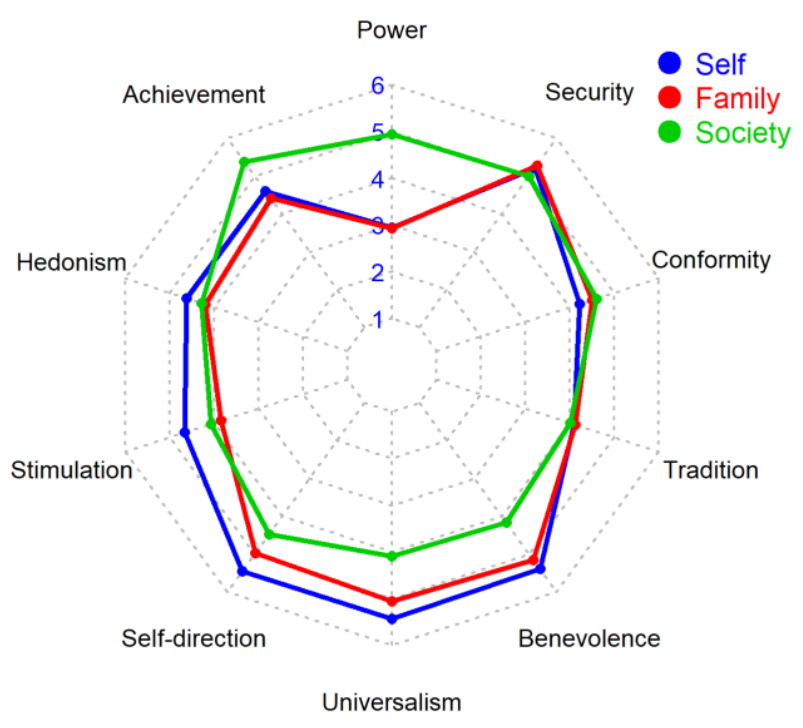

Figure 3. Perceived value importance for self, family, and country.

Structure of values. Finally, we tested whether the structure of Schwartz's (1992)

value model (see Figure 1) holds for the perceived familial and perceived societal values. To do this, we used Schwartz's recommended method of multidimensional scaling (MDS) with 
an approach suggested by Bilsky et al. (Bilsky \& Janik, 2010; Bilsky et al., 2011). That is, we computed all inter-item correlations and conducted MDS using the theory-based starting configurations provided by Schwartz's model. Consistent with previous value research (Gouveia et al., 2014b), we report the Tucker's congruence coefficient and the Stress-I values. Because the Stress-I values might not be suitable to assess model fit if a range of values are analyzed, we focus on Tucker's congruence coefficient, where values above .95 are considered as good, between .85 and .94 as fair (Lorenzo-Seva \& ten Berge, 2006). Tucker's congruence coefficient indicated good fit for the own values $(.996$, Stress-I $=.09)$, the perceived family values $(.996$, Stress-I $=.09)$, and perceived societal values $(.997$, Stress-I $=$ .08). More importantly however, the common space plots supported Schwartz' structure (Figure 4). Only small deviations within the higher order value types were found. For example, security was in all cases closer to benevolence and universalism than to power. However, small deviations are negligible, as long as the values types were all group together within the higher order value types (Bilsky et al., 2011). This was the case: achievement was for all three measurements of values positioned next to power; tradition, conformity, and security were next to each other, as were benevolence and universalism, and the three openness value types self-direction, stimulation, and hedonism. Overall, the model-consistent findings support the reliability of the three versions of the SSVS we used to measure own, perceived family, and perceived societal values. 

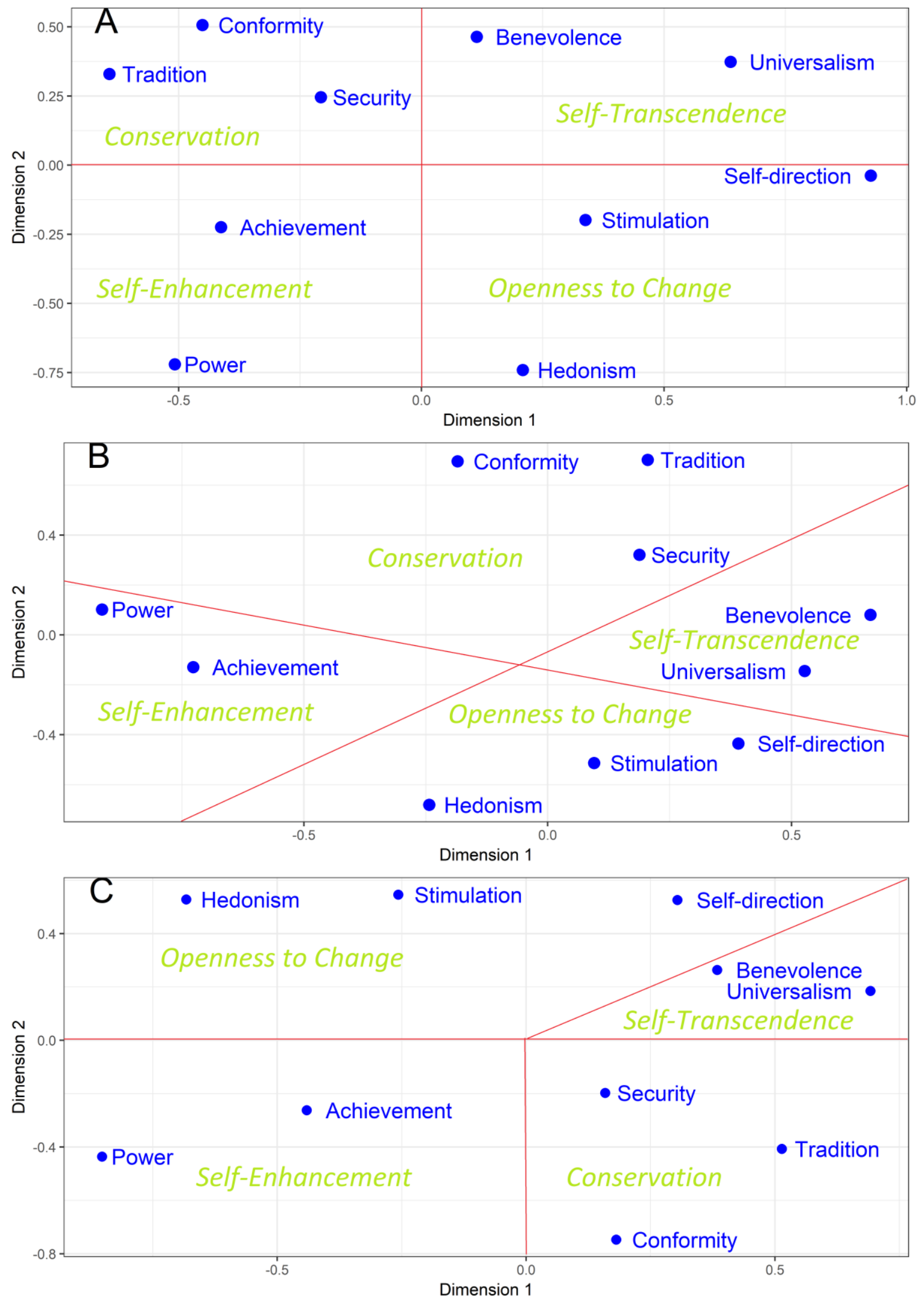

Figure 4. Common space plots for own values (panel A), perceived familial values (panel B), and perceived societal values (panel C). 
Summary. Study 1 provided our first test of potential misperceptions relating to values. The findings robustly supported the hypothesis that the misperceptions depend on value type, such that participants perceived benevolence and universalism to be more important for themselves in comparison to their family and particularly in comparison to their compatriots. Participants also perceived their country to attribute more importance to power and achievement values, but not their family, suggesting that the self-other differences are stronger for self-compatriot comparisons than for self-family comparisons. In the following studies, we replicate this initial evidence. This replication is also necessary because generalizing from student samples to the general public can be problematic (Hanel \& Vione, 2016), as students are younger and potentially more educated than members of their family and country. Thus, testing whether these initial findings hold in a representative sample could rule out potential age and educational effects.

\section{Study 2}

In Study 2, a representative sample within a large British city was asked how they perceive the values of the average person living in the same city. Study 2 overcame a limitation of Study 1, wherein the representative control group has completed a different value survey than our sample. Study 2 included the same survey for the comparisons. We expected that comparing personal values to perceptions of the values of people in one's own city would reveal the same patterns as our prior comparisons between personal values and perceptions of the values of people in one's own country. This focus on a city-level is useful given the potential greater concreteness and tangibility of cities for residents.

\section{Method}

Participants. In total, 1,184 participants from Greater Manchester ("Mancunians") took part in an online survey from all 10 boroughs of Greater Manchester. Participants were 640 women, 540 men, two indicated 'Other' and two preferred not to say. One hundred and thirty-three participants were aged 18-24, 211 were aged 25-34, 209 were aged 35-44, 234 
were aged 45-54, 206 were aged 55-64, 165 were aged 65-74, 24 were aged 75+, and two preferred not to say. One-thousand twelve participants $(85.9 \%)$ identified themselves as British, 33 as Pakistani (2.8\%), and 18 (1.5\%) as Chinese.

Material. Participants were first asked to complete the standard 21-item Portrait Values Questionnaire (PVQ; Schwartz et al., 2001). The internal consistencies were acceptable $(\alpha=.60-.73)$, except for self-direction $(\alpha=.41)$ and tradition $(\alpha=.36)$. Subsequently, we asked participants to fill in a similar 21-item PVQ, except that they now indicated to what extent each described person is like "a typical person living in Greater Manchester". For instance, the description "It is important to him to be rich. He wants to have a lot of money and expensive things" was answered on a scale from 1 (not at all like a typical person living in Greater Manchester) to 6 (very much like a typical person living in Greater Manchester). The internal consistencies were acceptable to good $(\alpha=.57-.78)$. Because the sample is already representative, all differences between own and perceived values simultaneously indicate a misperception of the Greater Mancunians' values. Participants completed an online survey and were compensated with a small amount of money. Study 2 was part of a larger survey in which additional societal and environmental concerns, civic engagement, and political attitudes were measured. This data was used in another manuscript to compare those who voted to leave Europe with those who voted to remain during the EU-Referendum in June 2016 (Hanel \& Wolf, 2018). In this other manuscript, no comparisons between own and perceived values are made. Also, the structure of values is not reported. Additionally, this study functioned as a comparator condition (i.e., no manipulation was applied) for an experiment that tested whether informing people that others either value self-transcendence values more strongly than self-enhancement values or vice versa would influence their civic engagement (see footnote 1 in the General Discussion for a short summary). 


\section{Results and Discussion}

Self-city value comparisons and accuracy of perceived values. We compared how participants perceived their own values compared to the values of their fellow citizens of their city, using a set of within-subject $t$-tests. The effect sizes were again computed using pooled standard deviations. Participants perceived their fellow Mancunians as valuing power, achievement, hedonism, and stimulation more than themselves, and as valuing self-direction, universalism, benevolence, tradition, conformity, and security less than themselves (Table 2). Further, the importance that participants ascribed to all 10 value types correlated with the importance of the perceived values $(.23<r<.43$, all $p \mathrm{~s}<.001)$. Overall, these results show that the pattern of self-city comparisons is similar to the pattern of self-country comparisons. As in Study 1, the correlation between the importance of the 10 value types participants attributed to the value types for themselves correlated positively with the self-country bias, $r(8)=.86$. This suggests that people underestimate the importance their compatriots ascribe to more important values and overestimate the importance of less important values. The pattern of results was the same across all 10 boroughs in Greater Manchester.

We then tested for potential age effects. First, we conducted a MANOVA with all 10 value types as dependent variables to test for age mean differences on values. The MANOVA was significant, $F(60,7062)=4.72, p<.001$, partial $\eta 2=.04$. We found the largest effects for achievement, $\mathrm{F}(6,1181)=22.21, \mathrm{p}<.001$, partial $\eta 2=.10$, and stimulation values, $\mathrm{F}(6,1181)$ $=18.66, \mathrm{p}<.001$, partial $\eta 2=.09$. Consistent with previous research (Robinson, 2012), younger people valued both stimulation and achievement more than older people. We report detailed results in the Supplemental Materials (Tables S1 to S3). Next, we explored whether there are age effects for the within-subject comparisons of the own and perceived values, by first computing the Cohen's ds, which we report in Table 2 (last column) separately for each age group (see Table S4). To test whether the self-other perceptions are similar across age groups, we correlated the 10 Cohen's ds obtained from each age group with those of the other 
age groups. The correlations were all very large, $r \mathrm{~s}(8)=.83-99, p \mathrm{~s} \leq .003$, indicating that age has little impact on how the values of the fellow citizens of their city are perceived relative to their own values. However, we observed two exceptions. Achievement was on average perceived by six out of the seven age groups to be of less importance for themselves than the citizens of their city (average $d=-0.40$ ), but not among the 18 to 24 year old participants, for whom a weak trend was in the opposite direction, $t(148)=1.41, p=.16, d=0.14$. The same pattern was observed for stimulation, which was on average perceived by six out of the seven age groups to be of less importance for themselves than the citizens of their city (average $d=$ 0.32), but not among the 18 to 24 year old participants, for whom a weak trend was in the opposite direction, $t(148)=0.86, p=.39, d=0.08$.

To test whether the pattern of results in Study 2 replicated the findings of Study 1, we correlated the effect sizes Cohen's $d$ for all 10 self-societal comparisons of Study 1 with the Cohen's $d$ s for the 10 self-city comparisons. The correlation was positive, $r(8)=.65$, suggesting that Study 2 indeed replicated Study 1. Finally, we found that the structure of Schwartz's (1992) value model holds for own and perceived values (see Supplemental Materials, Figure S1).

Table 2

Descriptive statistics and within-subject comparison of the perceived value importance for self and fellow citizens of their city

\begin{tabular}{lccrrr}
\hline & \multicolumn{2}{c}{ Mean (SD) } & $t$ & & Cohen's $d$ \\
& Self & City & & & \\
\hline Power & $2.82(1.14)$ & $3.58(1.09)$ & -20.34 & $* * *$ & -0.61 \\
Achievement & $3.48(1.22)$ & $3.85(1.03)$ & -9.38 & $* * *$ & -0.28 \\
Hedonism & $3.64(1.14)$ & $4.27(1.05)$ & -16.81 & $* * *$ & -0.50 \\
Stimulation & $3.46(1.24)$ & $3.79(1.04)$ & -8.10 & $* * *$ & -0.24 \\
Self-direction & $4.28(1.00)$ & $3.95(1.01)$ & 8.94 & $* * *$ & 0.26 \\
Universalism & $4.51(0.91)$ & $3.59(1.06)$ & 27.12 & $* * *$ & 0.80 \\
\hline
\end{tabular}




\begin{tabular}{llllll}
\hline Benevolence & $4.66(0.98)$ & $4.03(1.06)$ & 18.76 & $* * *$ & 0.56 \\
Tradition & $4.02(1.10)$ & $3.43(1.08)$ & 15.73 & $* * *$ & 0.47 \\
Conformity & $3.91(1.16)$ & $3.24(1.13)$ & 16.91 & $* * *$ & 0.50 \\
Security & $4.49(1.08)$ & $4.18(1.05)$ & 9.28 & $* * *$ & 0.28 \\
\hline
\end{tabular}

Note. All $d f \mathrm{~s}=1179$.

\section{Study 3}

Study 3 set out to extend our investigation to people from a non-Western country, Brazil (Hofstede, 2001). As described above, previous research found that misperceptions for traits in non-Western country are attenuated (Heine et al., 1999; Lee, 2012; Markus \& Kitayama, 1991). We therefore hypothesized that no self-other differences would occur for values in a non-Western country. We also explored how accurately Brazilians perceived their compatriots' values. In this study, we relied on a different model of values, Gouveia's functional theory (2013), to test whether the findings of Study 1 transcend the specific wording of Schwartz's (1992) value model.

\section{Method}

Participants. One-hundred and five Brazilian participants completed the survey $\left(M_{\text {age }}\right.$ $=30.92, S D=13.25$, age range $=17-73 ; 55$ women). Seventy-three participants were single, 20 married, four divorced, and eight "other". Six participants completed at least high school, 36 had yet an incomplete higher education, 35 a full higher education, and 28 had a postgraduate degree. None of the participants had lived abroad for more than three months.

Material and procedure. Participants completed a range of measures, with only a subset being relevant to the present study. We assessed values with the Basic Values Survey (Gouveia, 2003), which measures each of the six value sub-functions with three items (e.g., "SUCCESS. To reach your goals; to be efficient in everything you do.” [promotion value]). Participants were instructed to rate how important they consider each of the values as a guiding principle in their life. Responses were given on a 7-point scale ranging from 1 (completely unimportant) to 7 (of the utmost importance). In the compatriot's version of the 
value survey, participants were asked to rate how important they consider the values as guiding principles for a typical (native) Brazilian citizen, using the same 7-point response scale. The internal consistencies of the six value types were generally acceptable, both for the personal $(.60 \leq \alpha \mathrm{s} \leq .76)$ and country version $(.61 \leq \alpha \mathrm{s} \leq .71)$. In the country version, the internal consistencies of the perceived promotion sub-function was low, $\alpha=.45$, as were the internal consistencies of the own supra-personal $(\alpha=.33)$ and existence $(\alpha=.49)$ subfunctions. Participants were recruited through social networks, completed an online survey, and were not compensated.

Representative comparison group. For the representative comparison groups, we used data from another ongoing project (Liu \& Vilar, 2017), which consists of 1058 to 1072 participants (the number of respondents varies slightly across sub-functions). All participants completed the Basic Values Survey (Gouveia, 2003) along with a range of other measures unrelated to the present study.

\section{Results and Discussion}

Self-compatriots' value comparisons. The pattern of results of Studies 1 and 2 was largely replicated in a Brazilian sample using Gouveia's functional theory (2013; Table 3). Participants perceived the values which were most important to them, supra-personal and existence values, as less important for their compatriots than themselves, and promotion and excitement values as more important for their compatriots than themselves. This largely replicates the findings of Study 1 and 2 that universalism ( supra-personal) values were perceived as more important for oneself than for the compatriots, whereas power and achievement ( promotion) values were perceived as less important. Because of the low reliability of the supra-personal sub-function, we repeated the analysis with the three items separately. However, the pattern of results remained the same (all $p \mathrm{~s}<.001$ ). The correlation between own and perceived compatriots' values were again small $(-.06<r<.18)$, replicating 
the findings of Study 1. As in Studies 1 and 2, the importance participants attributed to the value types for themselves correlated positively with the self-country bias, $r(4)=.82$.

Accuracy of perceived compatriots' values. The accuracy of the perceived compatriots' values was similar to Studies 1 and 2. Compatriots' supra-personal, existence, and, somewhat surprisingly, normative values were underestimated, whereas excitement values were overestimated. The effect size for supra-personal values was particularly large, which is in line with previous findings that the self-other differences are stronger for positive traits in non-Western countries (Lee, 2012). Finally, we found that the structure of Gouveias's (2013) value model holds for own and perceived values (see Supplemental Materials, Figure S2).

Table 3

Descriptive statistics and comparison of perceived value importance for self and compatriots and with actual value importance

\begin{tabular}{lcccccc}
\hline & \multicolumn{3}{c}{ Mean (SD) } & \multicolumn{2}{c}{ t-value } & \multicolumn{2}{c}{ Cohen's ds } \\
& Self & Country & Representative & Self-Country & Country-Actual \\
\hline Excitement & $4.84(1.02)$ & $5.23(1.05)$ & 4.94 & $-2.87 * *$ & $2.78^{* *}$ & $-0.28 / 0.28$ \\
Suprapersonal & $5.75(0.71)$ & $3.97(1.30)$ & 5.56 & $13.24 * * *$ & $-12.55^{* * *}$ & $1.29 /-1.22$ \\
Interactive & $5.41(1.08)$ & $5.26(1.21)$ & 5.45 & 0.96 & -1.61 & $0.09 /-0.16$ \\
Promotion & $4.67(1.02)$ & $4.96(1.11)$ & 4.83 & $-1.97 *$ & 1.16 & $-0.19 / 0.12$ \\
Existence & $6.04(0.76)$ & $5.19(1.12)$ & 5.89 & $7.05 * * *$ & $-6.42^{* * *}$ & $0.69 /-0.63$ \\
Normative & $4.37(1.52)$ & $4.76(1.33)$ & 5.57 & -1.93 & $-6.22 * * *$ & $-0.19 /-0.61$ \\
\hline
\end{tabular}

Note. All $d f \mathrm{~s}=104$ for pairwise comparison. The first Cohen's d refers to self-country comparison, the second d refers to country-actual (representative) comparison, which is computed as $M_{d i f f} / S D$.

\section{Study 4}

Study 4 aimed to test whether the self-other differences and the misperceptions of other people's values would also hold for people judging the values of a country in which they are only temporarily living. Specifically, the sample included Brazilian students who 
were abroad at the time of data collection for at least six months. We relied again on the functional theory of values (Gouveia, 2013).

\section{Method}

Participants. Two-hundred sixty-eight Brazilian under- and postgraduate students completed the survey (158 females, 88 males, 22 missing). The participants were abroad at the time of data collection for at least six months $(n=120)$ or had finished their stay abroad (n $=148)$. Their mean age was 24.87 years $(S D=4.18)$. The majority went abroad to Western countries, with the UK $(n=59)$, Spain $(n=24)$, and USA $(n=24)$ being selected the most often. Students were from a wide range of scientific fields (e.g., medicine, psychology).

Material and procedure. Participants completed a range of measures, with only a subset being relevant for the present study. The personal and perceived (temporary) compatriots' values were again assessed with the Basic Values Survey (Gouveia, 2003); the instructions for participants' own values remained the same as in Study 3. In the country version of the value survey, participants were asked to rate how important they consider the values as guiding principles for the typical (native) citizen of the country in which they are currently living or had lived. The internal consistencies of the six value types were low to good, both for the personal $(.40 \leq \alpha \mathrm{s} \leq .69)$ and country version $(.49 \leq \alpha \mathrm{s} \leq .73)$. Participants were recruited through social networks, completed an online survey, and were not compensated.

Representative comparison group. For the representative comparison groups, we selected only those countries in which at least 20 of the participants were staying. For Spain, the UK, and USA, we used data from another ongoing project (Liu \& Vilar, 2017), which contained representative samples. The participants had completed a back-translated version of the Basic Values Survey (Gouveia, 2003; Gouveia et al., 2014a) in their native language. Study 4 was part of a larger survey in which additionally personality traits (Big-5) and several items regarding participants' abroad experience were measured. In another manuscript that is 
currently under review, the own values and traits of the participants are compared with the values of another sample of Brazilians who has not been abroad to identify differences between sojourners and non-sojourners (Vilar et al., 2017).

\section{Results and Discussion}

In a preliminary analysis, we tested whether those participants who were still abroad perceived compatriots' values differently from those whose stay abroad was over. However, none of the six interactions - one for each sub-function - reached significance $(p s>.10)$. We therefore collapsed both groups.

Self-compatriots' value comparisons. The pattern of results of Studies 1-3 was largely replicated for Brazilian immigrants using Gouveia's functional theory (2013; Table 4). Participants perceived their own interactive values, supra-personal, and existence values as more important than the values of the people in their host country, and promotion values and normative values as less important. The correlation between own and perceived compatriots' values were again small $(.06<r<.29)$. As in Studies 1 to 3 , the importance participants attributed to the value types for themselves correlated positively with the self-country bias, $r(4)=.82$

To test whether the pattern of results in Study 4 replicated the findings of Study 3, we correlated the effect sizes Cohen's $d$ for all 6 self-societal comparisons of Study 3 with the Cohen's $d$ s for the 6 comparisons of Study 4. The correlation was positive, $r(4)=.51$. Also, the effect sizes were in the same direction, except for the own-country comparison for excitement values.

Accuracy of perceived compatriots' values. In a next step, we tested the accuracy of participants' perception of the values of the country they were in (Spain, UK, or USA), using one-sample $t$-tests comparing the responses of our participants with the mean of the representative samples for each value types. Participants in all countries strongly overestimated promotion values, and participants in the UK and USA also overestimated 
excitement and normative values (Table 5). Overall, these findings replicated the results of the other studies, because promotion values are closely related to the power and achievement values in Schwartz's (1992) theory, whereas excitement values are closely related to hedonism and stimulation. Finally, we found that the structure of Gouveias's (2013) value model holds for own and perceived values (see Supplemental Materials, Figure S3).

Table 4

Descriptive statistics and within-subject comparison of the perceived value importance for self and country

\begin{tabular}{|c|c|c|c|c|c|c|}
\hline & \multicolumn{2}{|c|}{ Mean (SD) } & \multirow[t]{2}{*}{$\mathrm{df}$} & \multirow[t]{2}{*}{$\mathrm{t}$} & & \multirow[t]{2}{*}{ Cohen's c } \\
\hline & Self & Country & & & & \\
\hline Excitement & $5.19(0.87)$ & $5.02(1.07)$ & 266 & 2.25 & $*$ & 0.17 \\
\hline Suprapersonal & $5.78(0.78)$ & $5.40(1.01)$ & 266 & 5.85 & $* * *$ & 0.42 \\
\hline Interactive & $5.49(0.84)$ & $4.76(1.20)$ & 266 & 8.37 & $* * *$ & 0.71 \\
\hline Promotion & $4.81(0.97)$ & $5.38(0.96)$ & 266 & -7.69 & $* * *$ & -0.60 \\
\hline Existence & $5.98(0.71)$ & $5.79(0.83)$ & 266 & 3.34 & $* * *$ & 0.25 \\
\hline Normative & $4.25(1.37)$ & $5.00(1.02)$ & 266 & -8.19 & $* * *$ & -0.62 \\
\hline
\end{tabular}

Table 5

Descriptive statistics and comparisons of perceived importance of compatriots' values and actual value importance of representative sample

df $\quad$ Cohen's d

\begin{tabular}{|c|c|c|c|c|c|c|c|c|}
\hline & & & Perceived & Actual & & & & \\
\hline & & Excitement & $5.30(1.33)$ & 4.97 & 21 & 1.17 & & 0.25 \\
\hline$\infty$ & & Suprapersonal & $5.55(1.04)$ & 5.24 & 21 & 1.38 & & 0.30 \\
\hline ন & & Interactive & $4.92(1.05)$ & 5.33 & 21 & -1.82 & & -0.39 \\
\hline$\Xi$ & & Promotion & $5.48(0.77)$ & 4.37 & 21 & 6.81 & $* * *$ & 1.45 \\
\hline$\Xi$ & & Existence & $5.52(0.70)$ & 5.74 & 21 & -1.52 & & -0.32 \\
\hline $\bar{\omega}$ & & Normative & $4.76(1.28)$ & 4.53 & 21 & 0.84 & & 0.18 \\
\hline & & Excitement & $4.91(0.97)$ & 4.48 & 70 & 3.75 & $* * *$ & 0.45 \\
\hline.$\stackrel{\oplus}{\Xi}$ & $D_{00}$ & Suprapersonal & $5.35(1.03)$ & 4.96 & 70 & 3.16 & $* *$ & 0.37 \\
\hline & 运 & Interactive & $4.78(1.27)$ & 5.17 & 70 & -2.58 & $*$ & -0.31 \\
\hline
\end{tabular}




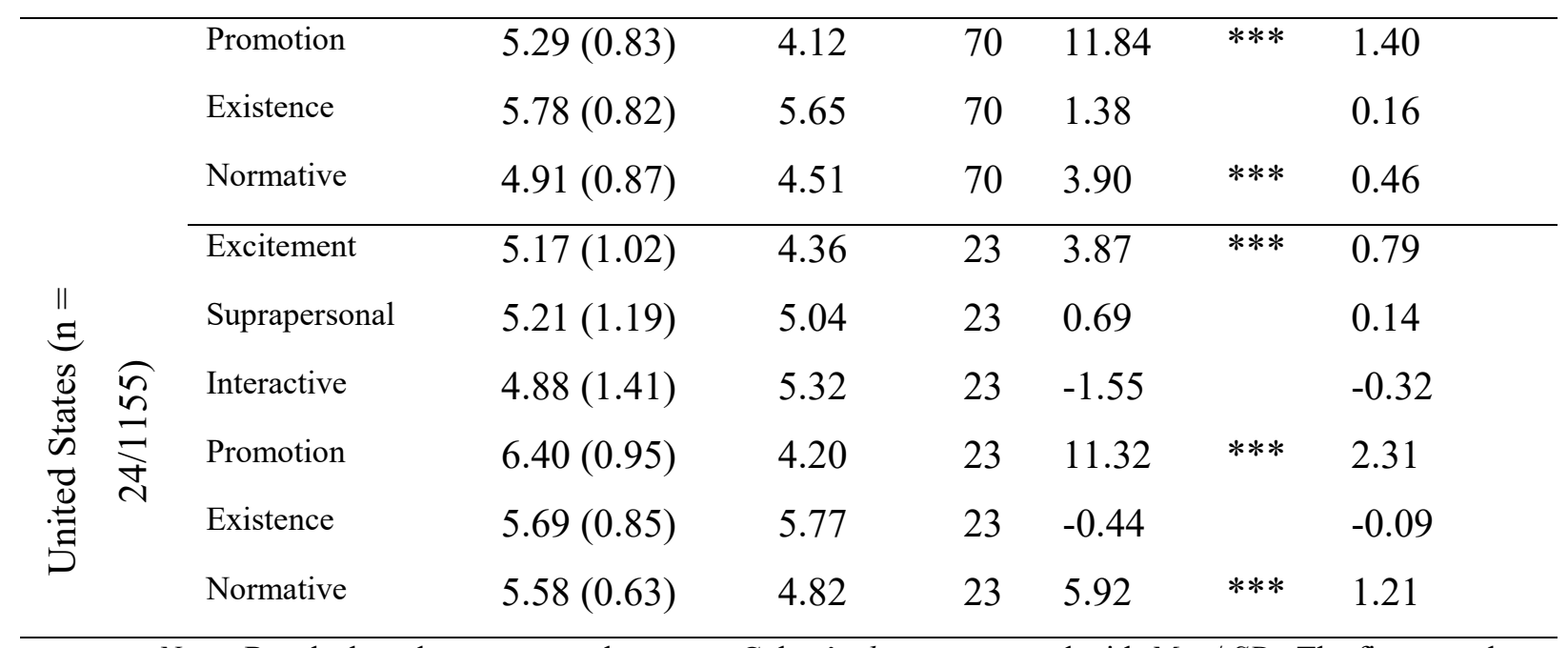

Note. Results based on one-sample $t$-tests. Cohen's $d$ was computed with $M_{\text {diff }} / S D$. The first sample

size in brackets after country name refers to students abroad, and the second sample size is the size of the representative sample.

\section{General Discussion}

The present research examined people's own values and their estimations of compatriots' values in various cultural contexts. Our results show that people partly misperceive the values of people living in the same city, and of compatriots. These misperceptions of city and compatriots' values are systematic and consistent across cultural contexts and value models. That is, people underestimate the importance their compatriots ascribe to more important values and overestimate the importance of less important values, in comparison to their own values, the actual values of the people living in the same city, and the actual values of their compatriots.

Additional findings from each study are of interest. Study 1 showed that the selffamily value differences were also systematic, although they were less pronounced: people perceive their families' values closer to their own values than their countries values. This new finding is in line with previous evidence that the family is close to the self-concept, facilitating similar overlapping biases in family- and self-perceptions (e.g., Tropp \& Wright, 2001). Study 2 mainly replicated these findings in a representative sample in a British city. 
Study 3 showed that systematic self-other differences can also be found in people from a non-Western country. This result stands in contrast with previous trait-based research reporting that people in non-Western countries show weaker or null perceived self-other differences (Heine et al., 1999; Lee, 2012; Markus \& Kitayama, 1991). This different pattern suggests that the perception of values and traits might be different. An alternative possibility, however, is that Brazilians are more westernized than East Asians, who participated in the above-cited cross-cultural research. Future research in East Asia is needed to address this question.

The findings of Study 4 also point to a role for cultural stereotypes in estimates of compatriots' values, at least among recent immigrants. Normative values (e.g., obedience, tradition) were overestimated in UK and USA, but not in Spain. This difference may have occurred because Spaniards are perceived as warmer and less organized than Britons and USAmericans. This suggestion is in line with previous research, where Spaniards were perceived by other Europeans to be more warm and less competent compared to Britons (Cuddy et al., 2009). Future research is needed to test whether values are also perceived differently for various groups. For example, abundant research has shown that people with different political attitudes (e.g., Democrats and Republicans) dislike each other (Iyengar, Sood, \& Lelkes, 2012) and assume that their opinion is superior to the opinions of the other group (Toner, Leary, Asher, \& Jongman-Sereno, 2013). We would therefore expect based on social identity theory (Tajfel \& Turner, 1986) that the perceived self-other differences is larger when rating the values of a disliked outgroup than when rating the values of one's own country, because seeing oneself as higher on important values might increase the feeling of superiority towards the outgroup. Indeed, it was found that religious people see other religious in-group members even more positively than themselves (Eriksson \& Funcke, 2014). Additionally, we found across all studies that the structure of perceived compatriots' values is almost identical to the structure of participants' own values. This is a novel finding 
which is especially interesting given the low correlation between participants' own and perceived compatriots' values, but in line with recent research that found that Schwartz's value structure could be replicated when the value priorities were rated by well-acquainted informants (Skimina \& Cieciuch, 2017). This is also an important extension concerning the universals in the structure of human values, which has recently been challenged (Raad et al., 2016). Previous studies claiming that the structure of human values is universal have relied on cross-cultural comparisons of own values (e.g., Bilsky et al., 2011; Schwartz, 1992). In the present research, we demonstrated that the structure is also the same when perceptions of values are considered. This finding suggests that the motivational compatibilities and conflicts observed for own values also hold for perceived country and family values. For example, universalism and benevolence values were perceived to be more compatible than universalism and power (Studies 1 and 2), and interactive and suprapersonal values were more compatible than interactive and promotion values (Studies 3 and 4). This similarity is important, because it allows researchers to derive specific hypotheses about the correlational pattern of perceived values with external variables (Gouveia, 2013; Schwartz, 1992). Specifically, because the structure of Schwartz's (1992) model was replicated in perceived family and compatriots' values, the correlational pattern should follow the sinusoidal wave pattern that is evident for own values (e.g., Boer \& Fischer, 2013; Hanel, Zacharopoulos, Mégardon, \& Maio, 2017; Schwartz, 1992).

Our findings suggest that more important values are also perceived as more characteristic for oneself, whereas less important values are perceived as less characteristic, similar to less characteristic or negative traits (Alicke et al., 1995, 2001). This result shows that it is not useful to treat values merely as positive constructs that are at least somewhat characteristic for everyone (Hitlin \& Piliavin, 2004). The differences matter. If all that mattered were for values to be at least somewhat characteristic for oneself, all of them would have been overestimated, perhaps as a function of their importance. However, the pattern of 
results was similar to the classic studies of traits (Alicke, 1985; Alicke et al., 1995): Some compatriots' values were perceived to be less important than for oneself, whereas other values were perceived to be more important. This suggests that the importance of the compatriots' values that are overestimated (e.g., power) are perceived as being less characteristic for oneself. This reasoning is corroborated by literature linking power values, which tend to be of lower self-importance, to negative outcomes (e.g., Schultz \& Zelezny, 1999; Zacharopoulos et al., 2018).

So far, we have not discussed potential causes for the self-other differences. The literature on the perception of other people's traits argued that the misperception is caused by a motivation to see oneself positively (Alicke et al., 1995; Brown, 2012). However, the findings of a similar recent survey suggest that the self-other differences for values is likely not caused by the motivation to see oneself positively: The perception of the compatriots' self-transcendence values was weakly positively correlated with impression formation and self-deceptive enhancement, whereas perceived self-enhancement values were weakly negatively correlated with the two measures (Common Cause Foundation, 2016; this study replicates the present findings). If the self-other differences for values were caused by the motivation to see oneself positively, the two bias measures would have been negatively correlated with perceived self-transcendence values and positively correlated with selfenhancement values. Thus, we do not think that a motivational basis causes this disparity between own and perceived values. Instead, structural reasons in the social surroundings are a likely alternative explanation why people overestimate the self-enhancement values of others. That is, people encounter strangers often in commercial environments such as shopping malls or in business contexts and see them expressing self-enhancement and hedonistic behaviors in the media or in advertisements. Thus, the environment may cause people to believe that others value self-enhancement values more instead of doing this to feel better about themselves. 
At first glance, this explanation seems to contradict the finding that power, achievement, or hedonism are considered to be less important than benevolence and universalism values (Schwartz \& Bardi, 2001): How do people exist in an environment that incentivizes behaviors expressing values that are less important to us? The cause putatively lies in the situations that shape our perceptions of the values of others versus the situations that shape our most cherished values. The situations that shape how we see others are those contexts in which we encounter people of low acquaintanceship to us. These encounters occur virtually through the media (where the focus is on negative events), and physically in diverse public commercial spaces (e.g., shopping malls, supermarkets), day-to-day workplace environments, and educational contexts. All of these spaces tend to emphasise work for monetary reward or goods. (Educational contexts prioritise success as a means for later reward, such as employment.) In contrast, our most precious places, within which personal values can be cultivated, are semi-private with family and friends. Here, self-transcending, nurturing concerns prevail (e.g., "charity starts at home"). Put simply, the stark difference between the spaces we occupy with strangers and the spaces we occupy with those nearest and dearest may exacerbate perceptions of self-other value differences.

This line of thought also points to an important future direction of research: What would happen if people are made aware that they underestimate the self-transcendence values and overestimate the self-enhancement values of others? We assume that this awareness would increase their willingness to engage more with others and to work in a voluntary capacity because perceiving others to be more selfish is negatively correlated with the motivation to engage in civic participation (Common Cause Foundation, 2016) ${ }^{1}$.

\footnotetext{
${ }^{1}$ Three authors of this paper have tested this hypothesis $(N=1,694$, unpublished data). We correctly informed participants in the experimental group that around $74 \%$ of their compatriots value self-transcendences more than self-enhancement values (cf. Common Cause Foundation, 2016). However, this did not affect their self-reported civic engagement and participation, social and environmental concerns, support for devolution, voting intentions, or satisfaction with life. However, in retrospect, the choice of the DVs was awkward: The DVs either referred to past behaviour or present beliefs, both constructs which are hardly be influenced by the
} 
It is also important to consider limitations of the studies we conducted. One limitation pertains to the low internal consistencies for some of the value types in Studies 2 to 4 . We do not think that the low internal consistencies pose a threat to our findings because the pattern of results remained mainly the same when we repeated the analysis on an item level. More important, however, the reliability was established through MDS in all of the studies (Figures 4, S1-S3). Low internal consistencies of value measures are also consistent with the literature. For example, Schwartz et al. (2001) explained the low internal consistencies of some value types (e.g., tradition) with few items for the value types in the PVQ. These researchers did not consider the low reliabilities to be a major problem because the value types show good convergent and discriminant validity.

Another limitation pertains to potential order effects. In all studies, participants were first asked to rate the importance of values for themselves, before rating them for their family, city, or society. However, whereas Studies 2 to 4 presented the own and perceived values in blocks on two subsequent pages, Study 1 presented the own and perceived values together. That is, participants first rated the importance of a value type for themselves, then for their family, and finally for their society, before moving on to the next value type. In other words, the three response options were almost presented simultaneously. Because the pattern of results was generally consistent across studies, we do not think that there are any order effects in place.

Conclusion. Perceptions of other people's values are often inaccurate. The importance that other people attribute to self-transcending / suprapersonal values is underestimated, whereas the importance of self-enhancement / promotion values is overestimated. Those findings hold across countries, sample types, and value models. This 
suggests that the values of other people are more selfless and less selfish than is often believed.

\section{References}

Alicke, M. D. (1985). Global self-evaluation as determined by the desirability and controllability of trait adjectives. Journal of Personality and Social Psychology, 49(6), $1621-1630$.

Alicke, M. D., Klotz, M. L., Breitenbecher, D. L., Yurak, T. J., \& Vredenburg, D. S. (1995). Personal contact, individuation, and the better-than-average effect. Journal of Personality and Social Psychology, 68(5), 804-825. https://doi.org/10.1037/00223514.68.5.804

Alicke, M. D., Vredenburg, D. S., Hiatt, M., \& Govorun, O. (2001). The "Better Than Myself Effect." Motivation and Emotion, 25(1), 7-22. https://doi.org/10.1023/A:1010655705069

Alvares, D. (2016). Crivella se compara com Doria e Kalil e diz que preservam "valores tradicionais" []. Folha de Sao Paulo. Retrieved from http://www1.folha.uol.com.br/poder/eleicoes-2016/2016/11/1828563-crivella-secompara-com-doria-e-kalil-e-diz-que-preservam-valores-tradicionais.shtml

Bilsky, W., \& Janik, M. (2010). The structural organization of human values: Evidence from the European Social Survey (ESS) - Updated. (Berichte aus der Arbeitseinheit Differentielle Psychologie und Persönlichkeitspsychologie, Institut für Psychologie ). Münster: Westfälische Wilhelms - Universität. Retrieved from https://www.researchgate.net/profile/Wolfgang_Bilsky/publication/317169157_The_st ructural_organization_of_human_values__evidence_from_the_European_Social_Survey_ESS__updated/links/59285864a6fdcc4443551b13/The-structural-organization-of-humanvalues-evidence-from-the-European-Social-Survey-ESS-updated.pdf 
Bilsky, W., Janik, M., \& Schwartz, S. H. (2011). The structural organization of human values - evidence from three rounds of the European Social Survey (ESS). Journal of CrossCultural Psychology, 42(5), 759-776. https://doi.org/10.1177/0022022110362757

Boer, D. (2014). SSVS-G. Deutsche Kurzskala des Wertefragebogens von S.H. Schwartz (Short Schwartz‘s Value Survey in German). In C. Kemper, M. Zenger, \& E. Brähler (Eds.), Handbuch Kurzskalen psychologischer Merkmale [Manual of psychological short scales]. Berlin: Medizinisch- Wissenschaftlichen Verlagsgesellschaft.

Boer, D., \& Fischer, R. (2013). How and when do personal values guide our attitudes and sociality? Explaining cross-cultural variability in attitude-value linkages. Psychological Bulletin, 139(5), 1113-1147. https://doi.org/10.1037/a0031347

Brown, J. D. (2012). Understanding the better than average effect: Motives (still) matter. Personality and Social Psychology Bulletin, 38(2), 209-219. https://doi.org/10.1177/0146167211432763

Common Cause Foundation. (2016). Perceptions Matter: The Common Cause UK Values Survey. London: Common Cause Foundation. Retrieved from http://valuesandframes.org/survey/

Cuddy, A. J. C., Fiske, S. T., Kwan, V. S. Y., Glick, P., Demoulin, S., Leyens, J.-P., ... Ziegler, R. (2009). Stereotype content model across cultures: Towards universal similarities and some differences. British Journal of Social Psychology, 48(1), 1-33. https://doi.org/10.1348/014466608X314935

Eriksson, K., \& Funcke, A. (2014). Humble self-enhancement: Religiosity and the betterthan-average effect. Social Psychological and Personality Science, 5(1), 76-83. https://doi.org/10.1177/1948550613484179

Eriksson, K., \& Funcke, A. (2015). A below-average effect with respect to American political stereotypes on warmth and competence. Political Psychology, 36(3), 341-350. https://doi.org/10.1111/pops.12093 
Feather, N. T., \& McKee, I. R. (2008). Values and prejudice: Predictors of attitudes towards Australian Aborigines. Australian Journal of Psychology, 60(2), 80-90. https://doi.org/10.1080/00049530701449513

Gouveia, V. V. (2003). The motivational nature of human values: Evidences of a new typology [in Portuguese]. Estudos de Psicologia, 8, 431-443.

Gouveia, V. V. (2013). Teoria funcionalista dos valores humanos [Functional theory of human values: Fundaments, applications and perspectives]. São Paulo: Casa do Psicólogo.

Gouveia, V. V., Milfont, T. L., \& Guerra, V. M. (2014a). Functional theory of human values: Testing its content and structure hypotheses. Personality and Individual Differences, 60, 41-47. https://doi.org/10.1016/j.paid.2013.12.012

Gouveia, V. V., Milfont, T. L., \& Guerra, V. M. (2014b). The functional theory of human values: From intentional overlook to first acknowledgement-A reply to Schwartz (2014). Personality and Individual Differences, 68, 250-253.

https://doi.org/10.1016/j.paid.2014.03.025

Gregg, A. P., Mahadevan, N., \& Sedikides, C. (2017). The SPOT effect: People spontaneously prefer their own theories. The Quarterly Journal of Experimental Psychology, 70(6), 996-1010. https://doi.org/10.1080/17470218.2015.1099162

Hanel, P. H. P., \& Vione, K. C. (2016). Do student samples provide an accurate estimate of the general public? PLOS ONE, 11(12), e0168354. https://doi.org/10.1371/journal.pone.0168354

Hanel, P. H. P., \& Wolf, L. J. (2018). Leavers and Remainers after Brexit: More united than divided after all? Manuscript under Review.

Hanel, P. H. P., Zacharopoulos, G., Mégardon, G., \& Maio, G. R. (2017). Detecting sinusoidal patterns from circumplex models of psychological constructs. Preprint. Retrieved from https://psyarxiv.com/wh92k/ 
Heine, S. J., Lehman, D. R., Markus, H. R., \& Kitayama, S. (1999). Is there a universal need for positive self-regard? Psychological Review, 106(4), 766. https://doi.org/10.1037/0033-295X.106.4.766

Heinemann, C. (2016). Horror-Clowns sind "Signal für Werteverfall in der Gesellschaft" [Horror-clowns are a 'sign' for the decline of values of the society]. Retrieved from http://www.deutschlandfunk.de/polizeigewerkschaft-horror-clowns-sind-signalfuer.694.de.html?dram:article_id=369815

Henrich, J., Heine, S. J., \& Norenzayan, A. (2010). The weirdest people in the world? Behavioral and Brain Sciences, 33(2-3), 61-83. https://doi.org/10.1017/S0140525X0999152X

Hitlin, S., \& Piliavin, J. A. (2004). Values: Reviving a dormant concept. Annual Review of Sociology, 30(1), 359-393. https://doi.org/10.1146/annurev.soc.30.012703.110640

Hofstede, G. (2001). Culture's consequences: Comparing values, behaviors, institutions and organizations across nations (2nd ed.). Thousand Oaks: Sage.

Iyengar, S., Sood, G., \& Lelkes, Y. (2012). Affect, not ideology: A social identity perspective on polarization. Public Opinion Quarterly, 76(3), 405-431. https://doi.org/10.1093/poq/nfs038

Lee, J. (2012). Trait desirability and cultural difference in the better-than-average effect. Asian Journal of Social Psychology, 15(4), 261-272. https://doi.org/10.1111/j.1467839X.2012.01381.x

Lindeman, M., \& Verkasalo, M. (2005). Measuring values with the short Schwartz's Value Survey. Journal of Personality Assessment, 85(2), 170-178. https://doi.org/10.1207/s15327752jpa8502_09

Liu, J. H., \& Vilar, R. (2017). Cross-cultural comparisons of the functional theory of human values. Unpublished dataset. 
Lorenzo-Seva, U., \& ten Berge, J. M. F. (2006). Tucker's congruence coefficient as a meaningful index of factor similarity. Methodology, 2(2), 57-64. https://doi.org/10.1027/1614-2241.2.2.57

Markus, H. R., \& Kitayama, S. (1991). Cultural variation in the self-concept. In J. Strauss \& G. R. Goethals (Eds.), The self: Interdisciplinary approaches (pp. 18-48). Springer New York. https://doi.org/10.1007/978-1-4684-8264-5_2

McCarthy, J. (2016). Americans remain pessimistic about state of moral values. Retrieved from http://www.gallup.com/poll/191858/americans-remain-pessimistic-state-moralvalues.aspx

Raad, B. D., Morales-Vives, F., Barelds, D. P. H., Oudenhoven, J. P. V., Renner, W., \& Timmerman, M. E. (2016). Values in a cross-cultural triangle: A comparison of value taxonomies in the Netherlands, Austria, and Spain. Journal of Cross-Cultural Psychology, 47(8), 1053-1075. https://doi.org/10.1177/0022022116659698

Schultz, P. W., \& Zelezny, L. (1999). Values as predictors of environmental attitudes: Evidence for consistency across 14 countries. Journal of Environmental Psychology, 19(3), 255-265. https://doi.org/10.1006/jevp.1999.0129

Schwartz, S. H. (1992). Universals in the content and structure of values: Theoretical advances and empirical tests in 20 countries. Advances in Experimental Social Psychology, 25, 1-65.

Schwartz, S. H. (2014). Functional theories of human values: Comment on Gouveia, Milfont, and Guerra (2014). Personality and Individual Differences, 68, 247-249. https://doi.org/10.1016/j.paid.2014.03.024

Schwartz, S. H., \& Bardi, A. (2001). Value hierarchies across cultures taking a similarities perspective. Journal of Cross-Cultural Psychology, 32(3), 268-290. https://doi.org/10.1177/0022022101032003002 
Schwartz, S. H., Melech, G., Lehmann, A., Burgess, S., Harris, M., \& Owens, V. (2001). Extending the cross-cultural validity of the theory of basic human values with a different method of measurement. Journal of Cross-Cultural Psychology, 32(5), 519542. https://doi.org/10.1177/0022022101032005001

Sedikides, C., Meek, R., Alicke, M. D., \& Taylor, S. (2014). Behind bars but above the bar: Prisoners consider themselves more prosocial than non-prisoners. British Journal of Social Psychology, 53(2), 396-403. https://doi.org/10.1111/bjso.12060

Skimina, E., \& Cieciuch, J. (2017). Value structure and priorities: Other-report account. Current Issues in Personality Psychology, 3(1). https://doi.org/10.5114/cipp.2018.72259

Souchon, N., Maio, G. R., Hanel, P. H. P., \& Bardin, B. (2017). Does spontaneous favorability to power (vs universalism) values predict spontaneous prejudice and discrimination? Journal of Personality, 85(5), 658-674. https://doi.org/DOI:10.1111/jopy.12269

Tajfel, H., \& Turner, J. C. (1986). The social identity theory of intergroup behavior. In S. Worchel \& W. G. Austin (Eds.), Psychology of intergroup relations (pp. 7-24). Chicago, IL: Nelson-Hall.

Tam, K.-P., Leung, A. K.- y., Kim, Y.-H., Chiu, C.-Y., Lau, I. Y.-M., \& Au, A. K. C. (2012). The better-than-average effect in Hong Kong and the United States: The role of personal trait importance and cultural trait importance. Journal of Cross-Cultural Psychology, 43(6), 915-930. https://doi.org/10.1177/0022022112443774

Tappin, B. M., \& McKay, R. T. (2017). The illusion of moral superiority. Social Psychological and Personality Science, 8(6), 623-631. https://doi.org/10.1177/1948550616673878

Toner, K., Leary, M. R., Asher, M. W., \& Jongman-Sereno, K. P. (2013). Feeling superior is a bipartisan issue: Extremity (not direction) of political views predicts perceived belief 
superiority. Psychological Science, 24(12), 2454-2462.

https://doi.org/10.1177/0956797613494848

Tropp, L. R., \& Wright, S. C. (2001). Ingroup identification as the inclusion of ingroup in the self. Personality and Social Psychology Bulletin, 27(5), 585-600.

https://doi.org/10.1177/0146167201275007

Varnum, M. E. W. (2015). Higher in status, (Even) better-than-average. Frontiers in Psychology, 6. https://doi.org/10.3389/fpsyg.2015.00496

Vilar, R., Liu, J., Araujo, R., Gouveia, V. V., Coelho, G. L. de H., Hanel, P. H. P., \& Monteiro, R. P. (2017). On the road: Personality and values of sojourners. Manuscript Submitted for Publication.

Zacharopoulos, G., Hanel, P. H. P., Wolfradt, U., Lancaster, T., Maio, G. R., \& Linden, D. E. J. (2018). The relation between human values and mental health: A behavioural and genetic study. Manuscript Submitted for Publication. 


\section{Supplemental Materials}

\section{Structure of Own and Perceived Values}

\section{Study 2}

Structure of values. Finally, we tested whether the structure of Schwartz' value model (Figure 1) holds for the perceived fellow citizens of their city values, again following the procedure described in Bilsky and Janik (2010). Tucker's congruence coefficient indicated good fit for both the own values $(.99$, Stress-I $=.14)$ and the perceived urban values $(.99$, Stress-I $=.14)$. Nevertheless, the common space plots supported again Schwartz's structure (Figure S1), with only small deviations within the higher order value types. 

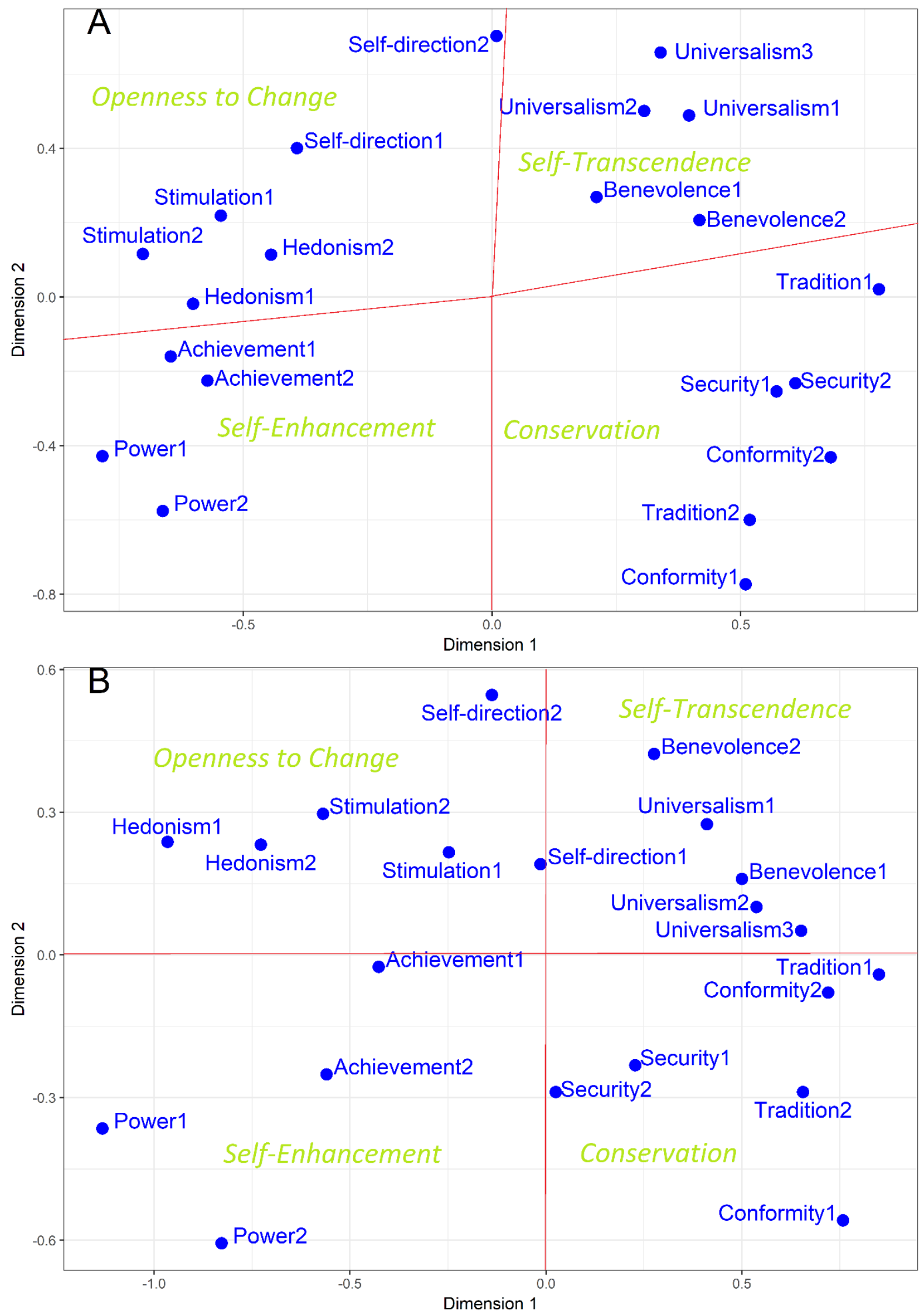

Figure S1. Common space plots for own values (panel A) and perceived citizens of their city values (panel B). 


\section{Study 3}

Structure of values. Finally, we tested whether the structure of the functional theory (Figure 2) holds for the perceived compatriots' values. For this, we performed a MDS for participants' own values and a second MDS for the perceived compatriots' values, this time following Gouveia et al. (2014a, 2014b). Tucker's congruence coefficient indicated good fit for both the own values $(.95$, Stress-I $=.32)$ and the perceived compatriots' values $(.95$, Stress-I $=.31$ ). The common space plots also revealed a very good fit (Figure S2). The survival needs were clearly distinguished from the thriving needs (see main diagonal lines in Figure S2) and the three values constituting each sub-function were grouped together. 

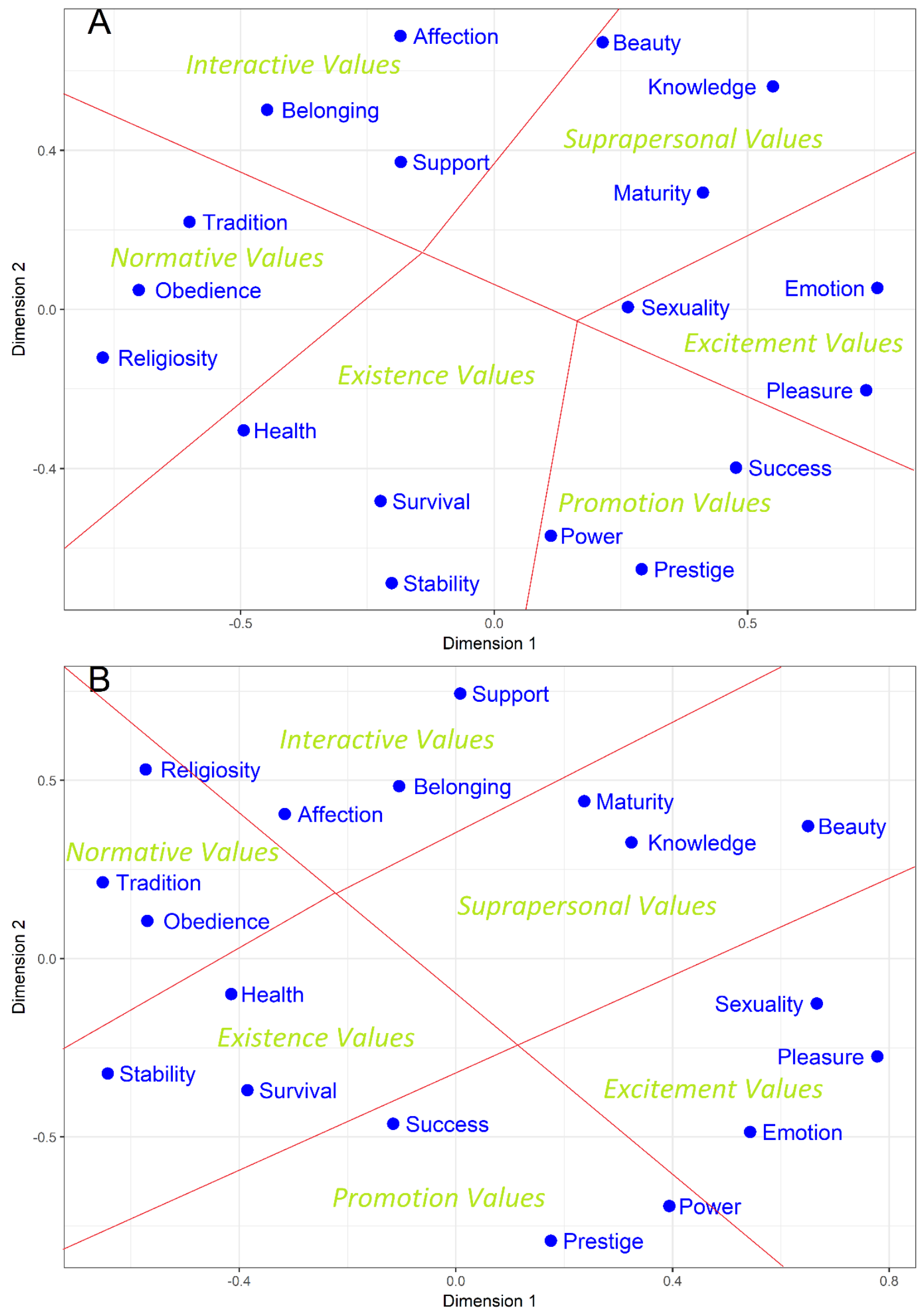

Figure S2. Common space plots for own values (panel A) and perceived compatriots' values (panel B). 


\section{Study 4}

Structure of values. Finally, we tested whether the structure of the functional theory (Figure 2) holds for perceived compatriots' values. For this, we performed a MDS for participants' own values and a second MDS for perceived compatriots' values, following Gouveia et al. (2014a, 2014b). Tucker's congruence coefficient indicated good fit for both the own values $(.94$, Stress- $\mathrm{I}=.35)$ and the perceived compatriots' values $(.94$, Stress- $\mathrm{I}=.35)$. The common space plots revealed a very good fit (Figure S3). The survival needs were clearly distinguished from the thriving needs (see long line in Figure S3) and the three values constituting each sub-function were grouped together. 

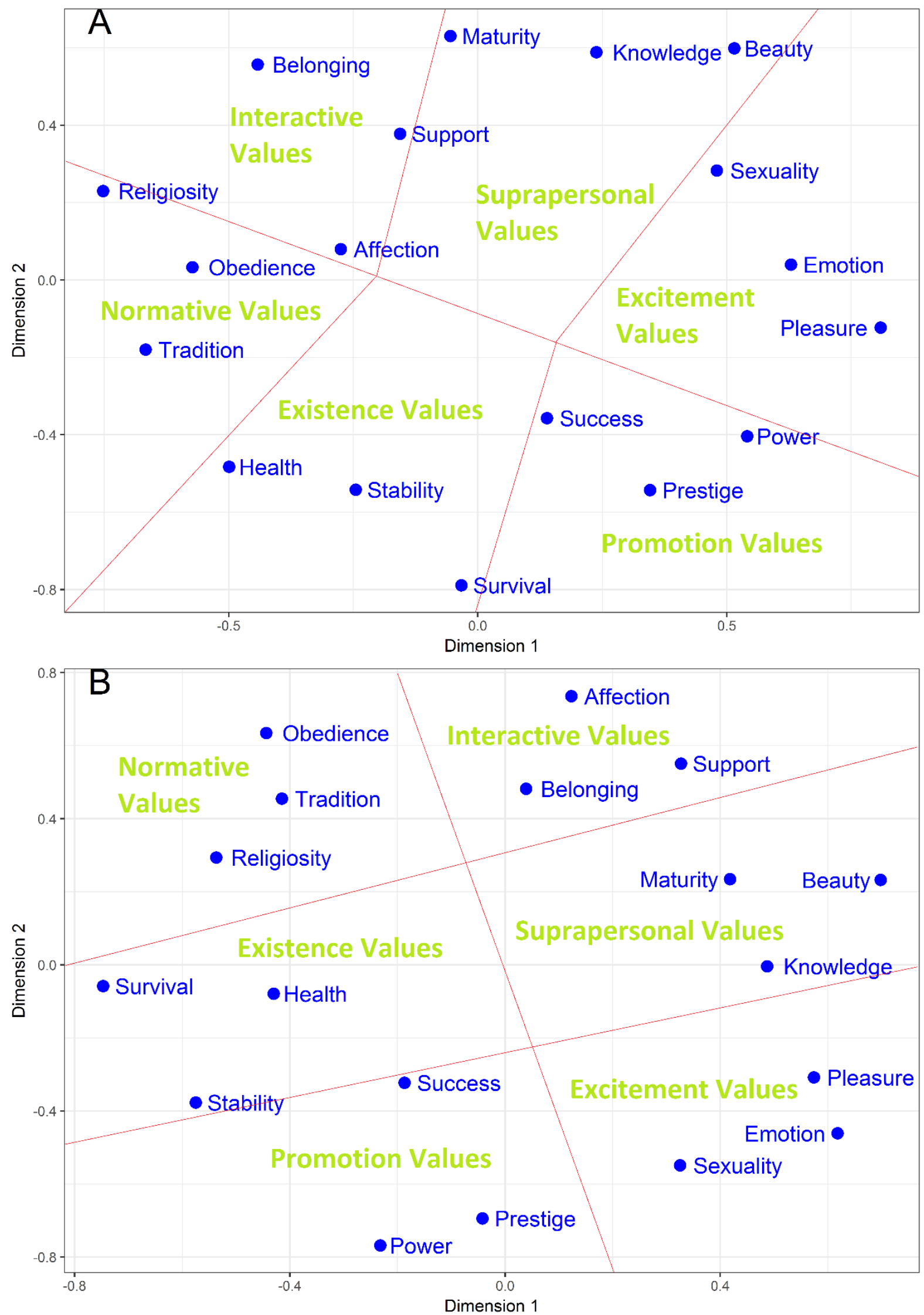

Figure S3. Common space plots for own values (panel A) and perceived compatriots' values (panel B). 


\section{Age Effects Study 2}

\section{Mean differences between age groups}

We tested whether the seven age groups would differ on the 10 value types. As a MANOVA was significant, we report in Table S1 the findings of 10 ANOVAs, one for each value type. Descriptive statistics can be found in Table S2 and multiple comparisons in Table S3.

Table S1

Results of 10 ANOVAs, one separately for each value type

\begin{tabular}{lllll}
\hline & df1, df2 & $F$ & $p$-value & partial $\eta^{2}$ \\
\hline Security & 6,1181 & 9.654 & .000 & .047 \\
Tradition & 6,1181 & 2.821 & .010 & .014 \\
Conformity & 6,1181 & 4.336 & .000 & .022 \\
Benevolence & 6,1181 & 2.081 & .053 & .010 \\
Universalism & 6,1181 & 1.280 & .263 & .006 \\
Self_direction & 6,1181 & 3.008 & .006 & .015 \\
Stimulation & 6,1181 & 18.660 & .000 & .087 \\
Hedonism & 6,1181 & 9.445 & .000 & .046 \\
Achievement & 6,1181 & 22.205 & .000 & .101 \\
Power & 6,1181 & 10.567 & .000 & .051 \\
\hline
\end{tabular}

Note. df1: Numerator degrees of freedom, df2: denominator degrees of freedom.

Table S2

Descriptive statistics

\begin{tabular}{lllrr}
\hline & Age range & $M$ & $S D$ & $\mathrm{n}$ \\
\hline Security & $18-24$ & 4.35 & 1.11 & 133 \\
& $25-34$ & 4.42 & 1.06 & 211 \\
& $35-44$ & 4.15 & 1.01 & 209 \\
& $45-54$ & 4.49 & 1.10 & 234 \\
& $55-64$ & 4.80 & 1.02 & 206 \\
& $65-74$ & 4.76 & 1.06 & 170 \\
& $75+$ & 4.94 & 0.83 & 25 \\
& Total & 4.50 & 1.08 & 1188 \\
& $18-24$ & 3.94 & 1.10 & 133 \\
& $25-34$ & 4.03 & 1.11 & 211 \\
& $35-44$ & 3.85 & 1.04 & 209 \\
& $45-54$ & 3.95 & 1.13 & 234 \\
& $55-64$ & 4.18 & 1.14 & 206 \\
\hline
\end{tabular}




\begin{tabular}{|c|c|c|c|c|}
\hline & $65-74$ & 4.07 & 1.07 & 170 \\
\hline & $75+$ & 4.54 & 1.01 & 25 \\
\hline & Total & 4.02 & 1.10 & 1188 \\
\hline \multirow[t]{8}{*}{ Conformity } & $18-24$ & 3.69 & 1.19 & 133 \\
\hline & $25-34$ & 3.83 & 1.17 & 211 \\
\hline & $35-44$ & 3.75 & 1.16 & 209 \\
\hline & $45-54$ & 3.85 & 1.12 & 234 \\
\hline & $55-64$ & 4.12 & 1.19 & 206 \\
\hline & $65-74$ & 4.12 & 1.12 & 170 \\
\hline & $75+$ & 4.32 & 1.25 & 25 \\
\hline & Total & 3.91 & 1.17 & 1188 \\
\hline \multirow[t]{8}{*}{ Benevolence } & $18-24$ & 4.79 & 1.07 & 133 \\
\hline & $25-34$ & 4.80 & 0.86 & 211 \\
\hline & $35-44$ & 4.56 & 0.99 & 209 \\
\hline & $45-54$ & 4.57 & 0.97 & 234 \\
\hline & $55-64$ & 4.73 & 0.97 & 206 \\
\hline & $65-74$ & 4.61 & 1.01 & 170 \\
\hline & $75+$ & 4.84 & 0.86 & 25 \\
\hline & Total & 4.67 & 0.97 & 1188 \\
\hline \multirow[t]{8}{*}{ Universalism } & $18-24$ & 4.67 & 0.95 & 133 \\
\hline & $25-34$ & 4.60 & 0.92 & 211 \\
\hline & $35-44$ & 4.50 & 0.85 & 209 \\
\hline & $45-54$ & 4.47 & 0.97 & 234 \\
\hline & $55-64$ & 4.45 & 0.93 & 206 \\
\hline & $65-74$ & 4.46 & 0.87 & 170 \\
\hline & $75+$ & 4.48 & 1.05 & 25 \\
\hline & Total & 4.52 & 0.92 & 1188 \\
\hline \multirow[t]{8}{*}{ Self-direction } & $18-24$ & 4.45 & 1.03 & 133 \\
\hline & $25-34$ & 4.43 & 1.03 & 211 \\
\hline & $35-44$ & 4.24 & 0.98 & 209 \\
\hline & $45-54$ & 4.12 & 1.05 & 234 \\
\hline & $55-64$ & 4.29 & 0.95 & 206 \\
\hline & $65-74$ & 4.15 & 0.95 & 170 \\
\hline & $75+$ & 4.44 & 1.13 & 25 \\
\hline & Total & 4.28 & 1.01 & 1188 \\
\hline \multirow[t]{8}{*}{ Stimulation } & $18-24$ & 4.09 & 1.17 & 133 \\
\hline & $25-34$ & 3.77 & 1.17 & 211 \\
\hline & $35-44$ & 3.65 & 1.19 & 209 \\
\hline & $45-54$ & 3.28 & 1.26 & 234 \\
\hline & $55-64$ & 3.07 & 1.19 & 206 \\
\hline & $65-74$ & 3.04 & 1.12 & 170 \\
\hline & $75+$ & 2.82 & 1.14 & 25 \\
\hline & Total & 3.44 & 1.24 & 1188 \\
\hline \multirow[t]{8}{*}{ Hedonism } & $18-24$ & 4.09 & 1.04 & 133 \\
\hline & $25-34$ & 3.87 & 1.11 & 211 \\
\hline & $35-44$ & 3.73 & 1.15 & 209 \\
\hline & $45-54$ & 3.45 & 1.10 & 234 \\
\hline & $55-64$ & 3.48 & 1.19 & 206 \\
\hline & $65-74$ & 3.38 & 1.11 & 170 \\
\hline & $75+$ & 3.16 & 1.07 & 25 \\
\hline & Total & 3.63 & 1.14 & 1188 \\
\hline
\end{tabular}




\begin{tabular}{rlllr}
\hline Achievement & $18-24$ & 4.24 & 1.11 & 133 \\
& $25-34$ & 3.83 & 1.14 & 211 \\
& $35-44$ & 3.56 & 1.28 & 209 \\
$45-54$ & 3.14 & 1.12 & 234 \\
$55-64$ & 3.15 & 1.17 & 206 \\
$65-74$ & 3.17 & 1.13 & 170 \\
Power & 2.80 & 1.35 & 25 \\
& $75+$ & 3.46 & 1.23 & 1188 \\
& Total & 3.22 & 1.19 & 133 \\
& $18-24$ & 3.09 & 1.17 & 211 \\
& $25-34$ & 2.89 & 1.26 & 209 \\
& $35-44$ & 2.57 & 1.03 & 234 \\
& $45-54$ & 2.55 & 1.05 & 206 \\
& $55-64$ & 2.62 & 0.96 & 170 \\
& $65-74$ & 2.36 & 1.24 & 25 \\
& $75+$ & 2.79 & 1.14 & 1188 \\
\hline Total & Note. Mean, SD: standard deviation, n: sample size per cell.
\end{tabular}

Table S3

Multiple comparisons (Sidak corrected)

\begin{tabular}{|c|c|c|c|c|c|}
\hline $\begin{array}{l}\text { Dependent } \\
\text { Variable }\end{array}$ & Age (I) & $\begin{array}{l}\text { Age comparison } \\
\text { group }(\mathrm{J})\end{array}$ & $\begin{array}{c}\text { Mean } \\
\text { Difference } \\
(\mathrm{I}-\mathrm{J})\end{array}$ & $S E$ & $p$ \\
\hline \multirow{29}{*}{ Security } & \multirow{6}{*}{$18-24$} & $25-34$ & -0.07 & 0.12 & 1.000 \\
\hline & & $35-44$ & 0.20 & 0.12 & .860 \\
\hline & & $45-54$ & -0.14 & 0.11 & .994 \\
\hline & & $55-64$ & -0.45 & 0.12 & .003 \\
\hline & & $65-74$ & -0.41 & 0.12 & .019 \\
\hline & & $75+$ & -0.59 & 0.23 & .196 \\
\hline & \multirow[t]{6}{*}{$25-34$} & $18-24$ & 0.07 & 0.12 & 1.000 \\
\hline & & $35-44$ & 0.27 & 0.10 & .165 \\
\hline & & $45-54$ & -0.07 & 0.10 & 1.000 \\
\hline & & $55-64$ & -0.38 & 0.10 & .005 \\
\hline & & $65-74$ & -0.33 & 0.11 & .044 \\
\hline & & $75+$ & -0.52 & 0.22 & .351 \\
\hline & \multirow[t]{6}{*}{$35-44$} & $18-24$ & -0.20 & 0.12 & .860 \\
\hline & & $25-34$ & -0.27 & 0.10 & .165 \\
\hline & & $45-54$ & -0.34 & 0.10 & .015 \\
\hline & & $55-64$ & -0.65 & 0.10 & .000 \\
\hline & & $65-74$ & -0.61 & 0.11 & .000 \\
\hline & & $75+$ & -0.79 & 0.22 & .009 \\
\hline & \multirow[t]{6}{*}{$45-54$} & $18-24$ & 0.14 & 0.11 & .994 \\
\hline & & $25-34$ & 0.07 & 0.10 & 1.000 \\
\hline & & $35-44$ & 0.34 & 0.10 & .015 \\
\hline & & $55-64$ & -0.31 & 0.10 & .045 \\
\hline & & $65-74$ & -0.26 & 0.11 & .240 \\
\hline & & $75+$ & -0.45 & 0.22 & .607 \\
\hline & \multirow[t]{5}{*}{$55-64$} & $18-24$ & 0.45 & 0.12 & .003 \\
\hline & & $25-34$ & 0.38 & 0.10 & .005 \\
\hline & & $35-44$ & 0.65 & 0.10 & .000 \\
\hline & & $45-54$ & 0.31 & 0.10 & .045 \\
\hline & & $65-74$ & 0.05 & 0.11 & 1.000 \\
\hline
\end{tabular}




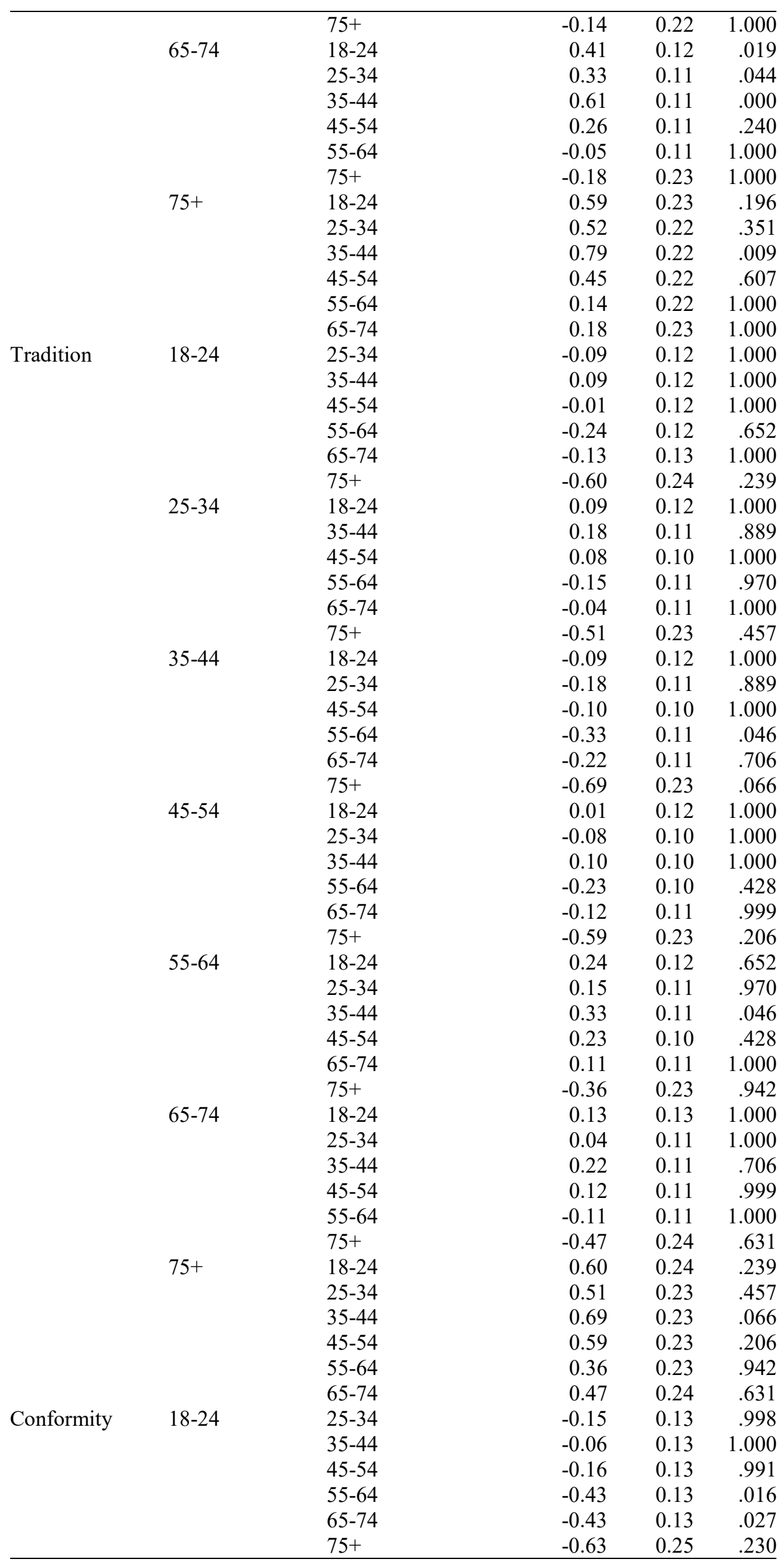




\begin{tabular}{|c|c|c|c|c|c|}
\hline & $25-34$ & $18-24$ & 0.15 & 0.13 & .998 \\
\hline & & $35-44$ & 0.08 & 0.11 & 1.000 \\
\hline & & $45-54$ & -0.01 & 0.11 & 1.000 \\
\hline & & $55-64$ & -0.29 & 0.11 & .214 \\
\hline & & $65-74$ & -0.29 & 0.12 & .295 \\
\hline & & $75+$ & -0.49 & 0.24 & 640 \\
\hline & $35-44$ & $18-24$ & 0.06 & 0.13 & 1.000 \\
\hline & & $25-34$ & -0.08 & 0.11 & 1.000 \\
\hline & & $45-54$ & -0.10 & 0.11 & 1.000 \\
\hline & & $55-64$ & -0.37 & 0.11 & .024 \\
\hline & & $65-74$ & -0.37 & 0.12 & .042 \\
\hline & & $75+$ & -0.57 & 0.24 & .351 \\
\hline & $45-54$ & $18-24$ & 0.16 & 0.13 & .991 \\
\hline & & $25-34$ & 0.01 & 0.11 & 1.000 \\
\hline & & $35-44$ & 0.10 & 0.11 & 1.000 \\
\hline & & $55-64$ & -0.27 & 0.11 & .251 \\
\hline & & $65-74$ & -0.27 & 0.12 & .342 \\
\hline & & $75+$ & -0.47 & 0.24 & .682 \\
\hline & $55-64$ & $18-24$ & 0.43 & 0.13 & .016 \\
\hline & & $25-34$ & 0.29 & 0.11 & .214 \\
\hline & & $35-44$ & 0.37 & 0.11 & .024 \\
\hline & & $45-54$ & 0.27 & 0.11 & .251 \\
\hline & & $65-74$ & 0.00 & 0.12 & 1.000 \\
\hline & & $75+$ & -0.20 & 0.25 & 1.000 \\
\hline & $65-74$ & $18-24$ & 0.43 & 0.13 & .027 \\
\hline & & $25-34$ & 0.29 & 0.12 & .295 \\
\hline & & $35-44$ & 0.37 & 0.12 & .042 \\
\hline & & $45-54$ & 0.27 & 0.12 & .342 \\
\hline & & $55-64$ & 0.00 & 0.12 & 1.000 \\
\hline & & $75+$ & -0.20 & 0.25 & 1.000 \\
\hline & $75+$ & $18-24$ & 0.63 & 0.25 & .230 \\
\hline & & $25-34$ & 0.49 & 0.24 & .640 \\
\hline & & $35-44$ & 0.57 & 0.24 & .351 \\
\hline & & $45-54$ & 0.47 & 0.24 & .682 \\
\hline & & $55-64$ & 0.20 & 0.25 & 1.000 \\
\hline & & $65-74$ & 0.20 & 0.25 & 1.000 \\
\hline Benevolence & $18-24$ & $25-34$ & 0.00 & 0.11 & 1.000 \\
\hline & & $35-44$ & 0.23 & 0.11 & .518 \\
\hline & & $45-54$ & 0.22 & 0.11 & .564 \\
\hline & & $55-64$ & 0.07 & 0.11 & 1.000 \\
\hline & & $65-74$ & 0.18 & 0.11 & .907 \\
\hline & & $75+$ & -0.05 & 0.21 & 1.000 \\
\hline & $25-34$ & $18-24$ & 0.00 & 0.11 & 1.000 \\
\hline & & $35-44$ & 0.23 & 0.09 & .269 \\
\hline & & $45-54$ & 0.22 & 0.09 & .296 \\
\hline & & $55-64$ & 0.07 & 0.10 & 1.000 \\
\hline & & $65-74$ & 0.18 & 0.10 & .761 \\
\hline & & $75+$ & -0.04 & 0.21 & 1.000 \\
\hline & $35-44$ & $18-24$ & -0.23 & 0.11 & .518 \\
\hline & & $25-34$ & -0.23 & 0.09 & .269 \\
\hline & & $45-54$ & -0.01 & 0.09 & 1.000 \\
\hline & & $55-64$ & -0.16 & 0.10 & .852 \\
\hline & & $65-74$ & -0.05 & 0.10 & 1.000 \\
\hline & & $75+$ & -0.28 & 0.21 & .985 \\
\hline & $45-54$ & $18-24$ & -0.22 & 0.11 & .564 \\
\hline & & $25-34$ & -0.22 & 0.09 & .296 \\
\hline & & $35-44$ & 0.01 & 0.09 & 1.000 \\
\hline & & $55-64$ & -0.15 & 0.09 & .888 \\
\hline & & $65-74$ & -0.04 & 0.10 & 1.000 \\
\hline & & $75+$ & -0.27 & 0.20 & .989 \\
\hline & $55-64$ & $18-24$ & -0.07 & 0.11 & 1.000 \\
\hline
\end{tabular}




\begin{tabular}{|c|c|c|c|c|c|}
\hline & & $25-34$ & -0.07 & 0.10 & 1.000 \\
\hline & & $35-44$ & 0.16 & 0.10 & .852 \\
\hline & & $45-54$ & 0.15 & 0.09 & .888 \\
\hline & & $65-74$ & 0.12 & 0.10 & .997 \\
\hline & & $75+$ & -0.11 & 0.21 & 1.000 \\
\hline & $65-74$ & $18-24$ & -0.18 & 0.11 & .907 \\
\hline & & $25-34$ & -0.18 & 0.10 & .761 \\
\hline & & $35-44$ & 0.05 & 0.10 & 1.000 \\
\hline & & $45-54$ & 0.04 & 0.10 & 1.000 \\
\hline & & $55-64$ & -0.12 & 0.10 & .997 \\
\hline & & $75+$ & -0.23 & 0.21 & .999 \\
\hline & $75+$ & $18-24$ & 0.05 & 0.21 & 1.000 \\
\hline & & $25-34$ & 0.04 & 0.21 & 1.000 \\
\hline & & $35-44$ & 0.28 & 0.21 & .985 \\
\hline & & $45-54$ & 0.27 & 0.20 & .989 \\
\hline & & $55-64$ & 0.11 & 0.21 & 1.000 \\
\hline & & $65-74$ & 0.23 & 0.21 & .999 \\
\hline Universalism & $18-24$ & $25-34$ & 0.07 & 0.10 & 1.000 \\
\hline & & $35-44$ & 0.17 & 0.10 & .872 \\
\hline & & $45-54$ & 0.20 & 0.10 & .609 \\
\hline & & $55-64$ & 0.21 & 0.10 & .554 \\
\hline & & $65-74$ & 0.20 & 0.11 & .709 \\
\hline & & $75+$ & 0.19 & 0.20 & 1.000 \\
\hline & $25-34$ & $18-24$ & -0.07 & 0.10 & 1.000 \\
\hline & & $35-44$ & 0.10 & 0.09 & .997 \\
\hline & & $45-54$ & 0.13 & 0.09 & .935 \\
\hline & & $55-64$ & 0.15 & 0.09 & .902 \\
\hline & & $65-74$ & 0.14 & 0.09 & .968 \\
\hline & & $75+$ & 0.12 & 0.19 & 1.000 \\
\hline & $35-44$ & $18-24$ & -0.17 & 0.10 & .872 \\
\hline & & $25-34$ & -0.10 & 0.09 & .997 \\
\hline & & $45-54$ & 0.03 & 0.09 & 1.000 \\
\hline & & $55-64$ & 0.04 & 0.09 & 1.000 \\
\hline & & $65-74$ & 0.03 & 0.09 & 1.000 \\
\hline & & $75+$ & 0.02 & 0.19 & 1.000 \\
\hline & $45-54$ & $18-24$ & -0.20 & 0.10 & 609 \\
\hline & & $25-34$ & -0.13 & 0.09 & .935 \\
\hline & & $35-44$ & -0.03 & 0.09 & 1.000 \\
\hline & & $55-64$ & 0.01 & 0.09 & 1.000 \\
\hline & & $65-74$ & 0.00 & 0.09 & 1.000 \\
\hline & & $75+$ & -0.01 & 0.19 & 1.000 \\
\hline & $55-64$ & $18-24$ & -0.21 & 0.10 & .554 \\
\hline & & $25-34$ & -0.15 & 0.09 & .902 \\
\hline & & $35-44$ & -0.04 & 0.09 & 1.000 \\
\hline & & $45-54$ & -0.01 & 0.09 & 1.000 \\
\hline & & $65-74$ & -0.01 & 0.09 & 1.000 \\
\hline & & $75+$ & -0.03 & 0.19 & 1.000 \\
\hline & $65-74$ & $18-24$ & -0.20 & 0.11 & .709 \\
\hline & & $25-34$ & -0.14 & 0.09 & .968 \\
\hline & & $35-44$ & -0.03 & 0.09 & 1.000 \\
\hline & & $45-54$ & 0.00 & 0.09 & 1.000 \\
\hline & & $55-64$ & 0.01 & 0.09 & 1.000 \\
\hline & & $75+$ & -0.02 & 0.20 & 1.000 \\
\hline & $75+$ & $18-24$ & -0.19 & 0.20 & 1.000 \\
\hline & & $25-34$ & -0.12 & 0.19 & 1.000 \\
\hline & & $35-44$ & -0.02 & 0.19 & 1.000 \\
\hline & & $45-54$ & 0.01 & 0.19 & 1.000 \\
\hline & & $55-64$ & 0.03 & 0.19 & 1.000 \\
\hline & & $65-74$ & 0.02 & 0.20 & 1.000 \\
\hline Self_direction & $18-24$ & $25-34$ & 0.03 & 0.11 & 1.000 \\
\hline & & $35-44$ & 0.21 & 0.11 & .697 \\
\hline
\end{tabular}




\begin{tabular}{|c|c|c|c|c|c|}
\hline & & $45-54$ & 0.33 & 0.11 & .049 \\
\hline & & $55-64$ & 0.17 & 0.11 & .954 \\
\hline & & $65-74$ & 0.30 & 0.12 & .179 \\
\hline & & $75+$ & 0.01 & 0.22 & 1.000 \\
\hline & $25-34$ & $18-24$ & -0.03 & 0.11 & 1.000 \\
\hline & & $35-44$ & 0.19 & 0.10 & .700 \\
\hline & & $45-54$ & 0.31 & 0.10 & .029 \\
\hline & & $55-64$ & 0.14 & 0.10 & .970 \\
\hline & & $65-74$ & 0.28 & 0.10 & .149 \\
\hline & & $75+$ & -0.01 & 0.21 & 1.000 \\
\hline & $35-44$ & $18-24$ & -0.21 & 0.11 & .697 \\
\hline & & $25-34$ & -0.19 & 0.10 & .700 \\
\hline & & $45-54$ & 0.12 & 0.10 & .994 \\
\hline & & $55-64$ & -0.05 & 0.10 & 1.000 \\
\hline & & $65-74$ & 0.09 & 0.10 & 1.000 \\
\hline & & $75+$ & -0.20 & 0.21 & 1.000 \\
\hline & $45-54$ & $18-24$ & -0.33 & 0.11 & .049 \\
\hline & & $25-34$ & -0.31 & 0.10 & .029 \\
\hline & & $35-44$ & -0.12 & 0.10 & .994 \\
\hline & & $55-64$ & -0.16 & 0.10 & .846 \\
\hline & & $65-74$ & -0.03 & 0.10 & 1.000 \\
\hline & & $75+$ & -0.32 & 0.21 & .952 \\
\hline & $55-64$ & $18-24$ & -0.17 & 0.11 & .954 \\
\hline & & $25-34$ & -0.14 & 0.10 & .970 \\
\hline & & $35-44$ & 0.05 & 0.10 & 1.000 \\
\hline & & $45-54$ & 0.16 & 0.10 & .846 \\
\hline & & $65-74$ & 0.14 & 0.10 & .988 \\
\hline & & $75+$ & -0.15 & 0.21 & 1.000 \\
\hline & $65-74$ & $18-24$ & -0.30 & 0.12 & .179 \\
\hline & & $25-34$ & -0.28 & 0.10 & .149 \\
\hline & & $35-44$ & -0.09 & 0.10 & 1.000 \\
\hline & & $45-54$ & 0.03 & 0.10 & 1.000 \\
\hline & & $55-64$ & -0.14 & 0.10 & .988 \\
\hline & & $75+$ & -0.29 & 0.21 & .985 \\
\hline & $75+$ & $18-24$ & -0.01 & 0.22 & 1.000 \\
\hline & & $25-34$ & 0.01 & 0.21 & 1.000 \\
\hline & & $35-44$ & 0.20 & 0.21 & 1.000 \\
\hline & & $45-54$ & 0.32 & 0.21 & .952 \\
\hline & & $55-64$ & 0.15 & 0.21 & 1.000 \\
\hline & & $65-74$ & 0.29 & 0.21 & .985 \\
\hline Stimulation & $18-24$ & $25-34$ & 0.32 & 0.13 & .292 \\
\hline & & $35-44$ & 0.44 & 0.13 & .020 \\
\hline & & $45-54$ & 0.80 & 0.13 & .000 \\
\hline & & $55-64$ & 1.02 & 0.13 & .000 \\
\hline & & $65-74$ & 1.04 & 0.14 & .000 \\
\hline & & $75+$ & 1.27 & 0.26 & .000 \\
\hline & $25-34$ & $18-24$ & -0.32 & 0.13 & .292 \\
\hline & & $35-44$ & 0.12 & 0.12 & .999 \\
\hline & & $45-54$ & 0.49 & 0.11 & .000 \\
\hline & & $55-64$ & 0.70 & 0.12 & .000 \\
\hline & & $65-74$ & 0.73 & 0.12 & .000 \\
\hline & & $75+$ & 0.95 & 0.25 & .003 \\
\hline & $35-44$ & $18-24$ & -0.44 & 0.13 & .020 \\
\hline & & $25-34$ & -0.12 & 0.12 & .999 \\
\hline & & $45-54$ & 0.37 & 0.11 & .025 \\
\hline & & $55-64$ & 0.58 & 0.12 & .000 \\
\hline & & $65-74$ & 0.61 & 0.12 & .000 \\
\hline & & $75+$ & 0.83 & 0.25 & .020 \\
\hline & $45-54$ & $18-24$ & -0.80 & 0.13 & .000 \\
\hline & & $25-34$ & -0.49 & 0.11 & .000 \\
\hline & & $35-44$ & -0.37 & 0.11 & .025 \\
\hline
\end{tabular}




\begin{tabular}{|c|c|c|c|c|c|}
\hline & & $55-64$ & 0.21 & 0.11 & .726 \\
\hline & & $65-74$ & 0.24 & 0.12 & .621 \\
\hline & & $75+$ & 0.46 & 0.25 & .748 \\
\hline & $55-64$ & $18-24$ & -1.02 & 0.13 & .000 \\
\hline & & $25-34$ & -0.70 & 0.12 & .000 \\
\hline & & $35-44$ & -0.58 & 0.12 & .000 \\
\hline & & $45-54$ & -0.21 & 0.11 & .726 \\
\hline & & $65-74$ & 0.03 & 0.12 & 1.000 \\
\hline & & $75+$ & 0.25 & 0.25 & 1.000 \\
\hline & $65-74$ & $18-24$ & -1.04 & 0.14 & .000 \\
\hline & & $25-34$ & -0.73 & 0.12 & .000 \\
\hline & & $35-44$ & -0.61 & 0.12 & .000 \\
\hline & & $45-54$ & -0.24 & 0.12 & .621 \\
\hline & & $55-64$ & -0.03 & 0.12 & 1.000 \\
\hline & & $75+$ & 0.22 & 0.25 & 1.000 \\
\hline & $75+$ & $18-24$ & -1.27 & 0.26 & .000 \\
\hline & & $25-34$ & -0.95 & 0.25 & .003 \\
\hline & & $35-44$ & -0.83 & 0.25 & .020 \\
\hline & & $45-54$ & -0.46 & 0.25 & .748 \\
\hline & & $55-64$ & -0.25 & 0.25 & 1.000 \\
\hline & & $65-74$ & -0.22 & 0.25 & 1.000 \\
\hline Hedonism & $18-24$ & $25-34$ & 0.21 & 0.12 & .854 \\
\hline & & $35-44$ & 0.36 & 0.12 & .079 \\
\hline & & $45-54$ & 0.64 & 0.12 & .000 \\
\hline & & $55-64$ & 0.61 & 0.12 & .000 \\
\hline & & $65-74$ & 0.71 & 0.13 & .000 \\
\hline & & $75+$ & 0.93 & 0.24 & .003 \\
\hline & $25-34$ & $18-24$ & -0.21 & 0.12 & .854 \\
\hline & & $35-44$ & 0.15 & 0.11 & .984 \\
\hline & & $45-54$ & 0.43 & 0.11 & .001 \\
\hline & & $55-64$ & 0.40 & 0.11 & .006 \\
\hline & & $65-74$ & 0.50 & 0.12 & .000 \\
\hline & & $75+$ & 0.71 & 0.24 & .054 \\
\hline & $35-44$ & $18-24$ & -0.36 & 0.12 & .079 \\
\hline & & $25-34$ & -0.15 & 0.11 & .984 \\
\hline & & $45-54$ & 0.28 & 0.11 & .174 \\
\hline & & $55-64$ & 0.25 & 0.11 & .377 \\
\hline & & $65-74$ & 0.35 & 0.12 & .055 \\
\hline & & $75+$ & 0.57 & 0.24 & .300 \\
\hline & $45-54$ & $18-24$ & -0.64 & 0.12 & .000 \\
\hline & & $25-34$ & -0.43 & 0.11 & .001 \\
\hline & & $35-44$ & -0.28 & 0.11 & .174 \\
\hline & & $55-64$ & -0.03 & 0.11 & 1.000 \\
\hline & & $65-74$ & 0.07 & 0.11 & 1.000 \\
\hline & & $75+$ & 0.29 & 0.24 & .995 \\
\hline & $55-64$ & $18-24$ & -0.61 & 0.12 & .000 \\
\hline & & $25-34$ & -0.40 & 0.11 & .006 \\
\hline & & $35-44$ & -0.25 & 0.11 & .377 \\
\hline & & $45-54$ & 0.03 & 0.11 & 1.000 \\
\hline & & $65-74$ & 0.10 & 0.12 & 1.000 \\
\hline & & $75+$ & 0.32 & 0.24 & .986 \\
\hline & $65-74$ & $18-24$ & -0.71 & 0.13 & .000 \\
\hline & & $25-34$ & -0.50 & 0.12 & .000 \\
\hline & & $35-44$ & -0.35 & 0.12 & .055 \\
\hline & & $45-54$ & -0.07 & 0.11 & 1.000 \\
\hline & & $55-64$ & -0.10 & 0.12 & 1.000 \\
\hline & & $75+$ & 0.22 & 0.24 & 1.000 \\
\hline & $75+$ & $18-24$ & -0.93 & 0.24 & .003 \\
\hline & & $25-34$ & -0.71 & 0.24 & .054 \\
\hline & & $35-44$ & -0.57 & 0.24 & .300 \\
\hline & & $45-54$ & -0.29 & 0.24 & .995 \\
\hline
\end{tabular}




\begin{tabular}{|c|c|c|c|c|c|}
\hline & & $55-64$ & -0.32 & 0.24 & .986 \\
\hline & & $65-74$ & -0.22 & 0.24 & 1.000 \\
\hline \multirow[t]{42}{*}{ Achievement } & $18-24$ & $25-34$ & 0.41 & 0.13 & .035 \\
\hline & & $35-44$ & 0.69 & 0.13 & .000 \\
\hline & & $45-54$ & 1.10 & 0.13 & .000 \\
\hline & & $55-64$ & 1.09 & 0.13 & .000 \\
\hline & & $65-74$ & 1.07 & 0.13 & .000 \\
\hline & & $75+$ & 1.44 & 0.25 & .000 \\
\hline & $25-34$ & $18-24$ & -0.41 & 0.13 & .035 \\
\hline & & $35-44$ & 0.28 & 0.11 & .261 \\
\hline & & $45-54$ & 0.69 & 0.11 & .000 \\
\hline & & $55-64$ & 0.69 & 0.11 & .000 \\
\hline & & $65-74$ & 0.66 & 0.12 & .000 \\
\hline & & $75+$ & 1.03 & 0.25 & .001 \\
\hline & $35-44$ & $18-24$ & -0.69 & 0.13 & .000 \\
\hline & & $25-34$ & -0.28 & 0.11 & .261 \\
\hline & & $45-54$ & 0.41 & 0.11 & .004 \\
\hline & & $55-64$ & 0.41 & 0.11 & .008 \\
\hline & & $65-74$ & 0.38 & 0.12 & .033 \\
\hline & & $75+$ & 0.76 & 0.25 & .047 \\
\hline & $45-54$ & $18-24$ & -1.10 & 0.13 & .000 \\
\hline & & $25-34$ & -0.69 & 0.11 & .000 \\
\hline & & $35-44$ & -0.41 & 0.11 & .004 \\
\hline & & $55-64$ & -0.01 & 0.11 & 1.000 \\
\hline & & $65-74$ & -0.03 & 0.12 & 1.000 \\
\hline & & $75+$ & 0.34 & 0.25 & .977 \\
\hline & $55-64$ & $18-24$ & -1.09 & 0.13 & .000 \\
\hline & & $25-34$ & -0.69 & 0.11 & .000 \\
\hline & & $35-44$ & -0.41 & 0.11 & .008 \\
\hline & & $45-54$ & 0.01 & 0.11 & 1.000 \\
\hline & & $65-74$ & -0.03 & 0.12 & 1.000 \\
\hline & & $75+$ & 0.35 & 0.25 & .974 \\
\hline & $65-74$ & $18-24$ & -1.07 & 0.13 & .000 \\
\hline & & $25-34$ & -0.66 & 0.12 & .000 \\
\hline & & $35-44$ & -0.38 & 0.12 & .033 \\
\hline & & $45-54$ & 0.03 & 0.12 & 1.000 \\
\hline & & $55-64$ & 0.03 & 0.12 & 1.000 \\
\hline & & $75+$ & 0.37 & 0.25 & .952 \\
\hline & $75+$ & $18-24$ & -1.44 & 0.25 & .000 \\
\hline & & $25-34$ & -1.03 & 0.25 & .001 \\
\hline & & $35-44$ & -0.76 & 0.25 & .047 \\
\hline & & $45-54$ & -0.34 & 0.25 & .977 \\
\hline & & $55-64$ & -0.35 & 0.25 & .974 \\
\hline & & $65-74$ & -0.37 & 0.25 & .952 \\
\hline \multirow[t]{17}{*}{ Power } & $18-24$ & $25-34$ & 0.13 & 0.12 & 999 \\
\hline & & $35-44$ & 0.33 & 0.12 & .162 \\
\hline & & $45-54$ & 0.66 & 0.12 & .000 \\
\hline & & $55-64$ & 0.67 & 0.12 & .000 \\
\hline & & $65-74$ & 0.60 & 0.13 & .000 \\
\hline & & $75+$ & 0.86 & 0.24 & .009 \\
\hline & $25-34$ & $18-24$ & -0.13 & 0.12 & .999 \\
\hline & & $35-44$ & 0.20 & 0.11 & .798 \\
\hline & & $45-54$ & 0.52 & 0.11 & .000 \\
\hline & & $55-64$ & 0.54 & 0.11 & .000 \\
\hline & & $65-74$ & 0.47 & 0.12 & .001 \\
\hline & & $75+$ & 0.73 & 0.24 & .042 \\
\hline & $35-44$ & $18-24$ & -0.33 & 0.12 & .162 \\
\hline & & $25-34$ & -0.20 & 0.11 & .798 \\
\hline & & $45-54$ & 0.33 & 0.11 & .042 \\
\hline & & $55-64$ & 0.34 & 0.11 & .039 \\
\hline & & $65-74$ & 0.28 & 0.12 & .293 \\
\hline
\end{tabular}




\begin{tabular}{rlrrr}
\hline $45-54$ & $75+$ & 0.53 & 0.24 & .397 \\
& $18-24$ & -0.66 & 0.12 & .000 \\
& $25-34$ & -0.52 & 0.11 & .000 \\
& $35-44$ & -0.33 & 0.11 & .042 \\
& $55-64$ & 0.01 & 0.11 & 1.000 \\
& $65-74$ & -0.05 & 0.11 & 1.000 \\
& $75+$ & 0.21 & 0.23 & 1.000 \\
& $18-24$ & -0.67 & 0.12 & .000 \\
& $25-34$ & -0.54 & 0.11 & .000 \\
& $35-44$ & -0.34 & 0.11 & .039 \\
& $45-54$ & -0.01 & 0.11 & 1.000 \\
& $65-74$ & -0.06 & 0.12 & 1.000 \\
& $75+$ & 0.19 & 0.24 & 1.000 \\
& $18-24$ & -0.60 & 0.13 & .000 \\
& $25-34$ & -0.47 & 0.12 & .001 \\
& $35-44$ & -0.28 & 0.12 & .293 \\
& $45-54$ & 0.05 & 0.11 & 1.000 \\
& $55-64$ & 0.06 & 0.12 & 1.000 \\
& $75+$ & 0.26 & 0.24 & .999 \\
& $18-24$ & -0.86 & 0.24 & .009 \\
& $25-34$ & -0.73 & 0.24 & .042 \\
& $35+44$ & -0.53 & 0.24 & .397 \\
& $45-54$ & -0.21 & 0.23 & 1.000 \\
& $55-64$ & -0.19 & 0.24 & 1.000 \\
& $65-74$ & -0.26 & 0.24 & .999 \\
\hline
\end{tabular}

Note. SE: Standard error.

\section{Age effects: Perceived value importance for self and fellow citizens of their city}

Table S4

Cohen's d for self-other comparisons, separately for each age group

\begin{tabular}{lrrrrrrr}
\hline & $18-24$ & $25-34$ & $35-44$ & $45-54$ & $55-64$ & $65-74$ & $75+$ \\
& & & & & & & \\
\hline Power & -0.53 & -0.67 & -0.56 & -0.70 & -0.59 & -0.55 & -0.68 \\
Achievement & 0.14 & -0.21 & -0.18 & -0.46 & -0.39 & -0.45 & -0.72 \\
Hedonism & -0.40 & -0.34 & -0.41 & -0.54 & -0.65 & -0.69 & -0.55 \\
Stimulation & 0.08 & -0.19 & -0.16 & -0.23 & -0.48 & -0.44 & -0.43 \\
Self-direction & 0.32 & 0.21 & 0.19 & 0.28 & 0.32 & 0.23 & 0.37 \\
Universalism & 0.76 & 0.70 & 0.84 & 0.91 & 0.76 & 0.89 & 0.87 \\
Benevolence & 0.50 & 0.56 & 0.57 & 0.58 & 0.56 & 0.58 & 0.78 \\
Tradition & 0.35 & 0.32 & 0.32 & 0.60 & 0.57 & 0.56 & 0.79 \\
Conformity & 0.30 & 0.34 & 0.39 & 0.58 & 0.61 & 0.77 & 0.75 \\
Security & 0.23 & 0.23 & 0.12 & 0.29 & 0.43 & 0.35 & 0.37 \\
\hline
\end{tabular}

Note. Columns present all seven age groups. 